\title{
Biophysical Aspects of the Nonsynaptic Epileptiform Activity
}

\author{
Antônio-Carlos G. Almeida ${ }^{1}$, Antônio M. Rodrigues' ${ }^{1}$, Mário A. Duarte ${ }^{1}$, \\ Gilcélio da Silveira1, Fulvio A. Scorza ${ }^{2}$, Ricardo M. Arida², \\ Jaderson C. Costa ${ }^{3}$ and Esper A. Cavalheiro ${ }^{2}$ \\ ${ }^{1}$ Universidade Federal de São João del-Rei \\ 2 Universidade Federal de São Paulo \\ 3Pontifícia Universidade Católica do Rio Grande do Sul \\ Brazil
}

\section{Introduction}

Since the demonstration that the hippocampus slice exposed to low calcium external solution is able to sustain nonsynaptic epileptiform activity, it has been accepted that nonsynaptic interactions may be sufficient, in some conditions, for generating seizure like activity in cortical network. Recently, evidences have suggested that the reductions in calcium are not essential for nonsynaptic mechanisms to contribute to epileptic activity. Therefore, evidences allow demonstrating that the conjoint actuation of nonsynaptic mechanisms and nonsynaptic connections are able to induce and sustain seizures. The nonsynaptic mechanisms considered in this context are all mechanisms which are not directly involved with synaptic transmission, but comprehending important action on the homeostasis equilibrium and, consequently, on the neuronal excitability.

The non-synaptic connections are all types of neuronal coupling that are not mediated by synaptic transmission. The concomitant actuation of nonsynaptic mechanisms and connections seems to be a relevant process for the seizure intensity modulation. Therefore, it may be conjectured that the nonsynaptic mechanisms and connections could be considered a natural target for investigations aiming to control refractory seizures. Within this perspective, the scope of the present chapter will cover the following topics:

- nonsynaptic events: experimental induction and electrophysiological characteristics;

- nonsynaptic mechanisms;

- nonsynaptic connections;

- biophysical aspects of the nonsynaptic epileptiform activities;

- $\quad$ possible targets for controlling refractory seizures.

\section{Nonsynaptic epileptiform events}

In in vivo experiments, chemically induced focal cortical seizures were observed to be sometimes preceded by small reductions in $\left[\mathrm{Ca}^{2+}\right]_{\mathrm{o}}$ and to become intense during the paroxysms (Heinemann et al., 1977; Krnjevic et al., 1980). Those findings lead to suspect that 
the calcium reduction may influence the course to the paroxysms. As the description by Jefferys \& Haas (1982) and Taylor \& Dudek (1982) show, it is well known that the hippocampus slice exposed to low calcium external solution is able to sustain nonsynaptic epileptiform activity. Based on the fact that low $\mathrm{Ca}^{2+}$ seizures occur in conditions of suppressed excitatory synaptic transmission, experimental findings demonstrate that nonsynaptic interactions may be sufficient, in some situations, for generating seizurelike activity in cortical network (Konnerth et al., 1986). More recently, evidences have suggested that the reductions in calcium are not essential for nonsynaptic mechanisms to contribute to epileptic activity (Bikson et al., 2002). Therefore, the nonsynaptic connections may have wider relevance than it could be initially suspected.

The nonsynaptic epileptiform activity was first observed in CA1 region of hippocampus slice involving the use of solutions with low $\left[\mathrm{Ca}^{2+}\right]$. Later, observations of the occurrence of prolonged field bursts in the dentate gyrus (DG) have been reported (Schweitzer et al., 1992). These authors pointed out the effect of deletion of $\mathrm{Ca}^{2+}$ from the bath solution on burst firing in CA3, CA1, and DG. When a calcium-free $5 \mathrm{mM}\left[\mathrm{K}^{+}\right]_{\mathrm{o}}$ solution was used, spontaneous bursts could still be observed in CA3 and CA1, but not in DG. However, at 9 $\mathrm{mM}\left[\mathrm{K}^{+}\right]_{o}$, although absent in CA3 and CA1, in DG spontaneous bursts characterized by an abrupt prolonged negative shift in the extracellular field potential could be observed followed by the appearance of large paroxysmal population spikes. The DG spontaneous bursts exhibited similarity to the "maximal dentate activation" (MDA), observed in vivo in the same region (Somjen et al., 1985; Stringer et al., 1989, 1991; Stringer \& Lothman, 1991). Therefore, the ability of each region to generate or sustain nonsynaptic epileptiform activity depends on the circumstances, more specifically on the level of calcium reduction and potassium increase.

In the hippocampus, especially in the DG, the tight packing of the cell bodies of neurons and glial cells constitutes an adequate substrate for the nonsynaptic connections. In highpotassium and zero- $\mathrm{Ca}^{2+}$ conditions the granule cells have some endogenous bursting capabilities able to sustain synchronization and, consequently, spontaneous epileptiform activity (Pan \& Stringer, 1996). As these observations have been made in the absence of synaptic transmission, because $\mathrm{Ca}^{2+}$ has been deleted from the bath solution, synchronization mechanisms must have nonsynaptic origin (Schweitzer et al., 1992; Pan \& Stringer, 1996) and could be mediated by gap-junctions, ionic fluctuations, or field effect.

It is known that the electrical signaling in neurons and glial cells is based on the activities of the ion pumps and carriers that establish transmembrane ionic gradients, and on the operation of ionic channels that generate current and voltage response based on electrodiffusion. Therefore, the cellular mechanisms described in the present study and investigated in the context of the epilepsy, by means of a computational simulation, are: membrane ionic currents, $\mathrm{Na}^{+} / \mathrm{K}^{+}$-ATPase, cotransporters, and exchangers. The cell activity of the network was nonsynaptically connected using extracellular electrodiffusion calculation, as well as the electric field effect and the gap-junctional coupling.

\subsection{Experimental induction and electrophysiological characteristics 2.1.1 Inducing non-synaptic epileptiform activity and experimental apparatus}

Hippocampal slices from Wistar rats were prepared (4-6 weeks old, male). After eutanized in a $\mathrm{CO}_{2}$ chamber, the brains were removed. Transverse slices $(400 \mu \mathrm{m})$ through the hippocampus were cut with a tissue chopper. After cutting, slices were stored in an oxygenated holding chamber for $\geq 1 \mathrm{~h}$ before recording. All recordings were acquired in an 
interface-chamber and continuously perfused with artificial cerebrospinal fluid (ACSF) at $32^{\circ} \mathrm{C}$ under a stream of humidified $95 \% \mathrm{O}_{2} / 5 \% \mathrm{CO}_{2}$. Composition of the ACSF was (in mM): $\mathrm{NaCl} 127, \mathrm{KCl} 2, \mathrm{MgSO}_{4} 1.5, \mathrm{KH}_{2} \mathrm{PO}_{4} 1.1, \mathrm{NaHCO}_{3} 26, \mathrm{CaCl}_{2} 2$ and glucose 10. All solutions were bubbled constantly with 95\% O2/5\% CO2. Slices were allowed to equilibrate for $1 \mathrm{~h}$ in normal ACSF. Recording electrodes were made of microfilament capillary thin-walled glass (0.9 mm ID, $1.2 \mathrm{~mm}$ OD) pulled on a micropipette puller (DMZ Universal Puller - ZeitzInstruments). Electrodes were filled with $2 \mathrm{M} \mathrm{NaCl}$ and had impedances between 5 and 10 $\mathrm{M} \Omega$. Recording electrodes were placed in the cell body layer of the region of interest. Nonsynaptic epileptiform activity was induced in the hippocampus by changing to ACSF containing 0 -added calcium and high potassium. The potassium was raised to $6 \mathrm{mM}$ to induce epileptiform activity in the CA1 region and was raised to $8 \mathrm{mM}$ to induce epileptiform activity in the dentate gyrus. The non-synaptic epileptiform activity can take more than an hour to appear, but once it appears, the interval between field bursts and the burst duration remain stable for many hours (Bikson et al., 1999; Pan \& Stringer, 1996).

In our laboratory, the interface-chamber is a variant of those used in several studies aimed at studying with in vitro slices (Pan \& Stringer, 1996; Schwartzkroin, 1975). The chamber consists of two coupled modules: the perfusion module and the heating module. The slice perfusion module (top view of the chamber, Fig. 1) consists of two cylinders and an acrylic base, which attaches superiorly to the heating module (see side view of the chamber, Fig. 1). The central cylinder is where a Millipore membrane $(0.4 \mu \mathrm{m}$ Millicell culture plate inserts; Milleppori, Bedford, MA, USA) is inserted. The slices are deposited on the membrane. The region in between the membrane and the acrylic base has approximately $0.34 \mathrm{ml}$, allowing the solution in contact with the slices, through the membrane, to be constantly renewed. The acrylic base has small holes through which carbogen, after crossing the water bath of the heating module, can humidify and oxygenate the slices. A disc-shaped lid covers the perfusion module ensuring homogeneity of the environment surrounding the slice. The lid has a central hole that allows insertion of the recording electrode and the carbogen release.
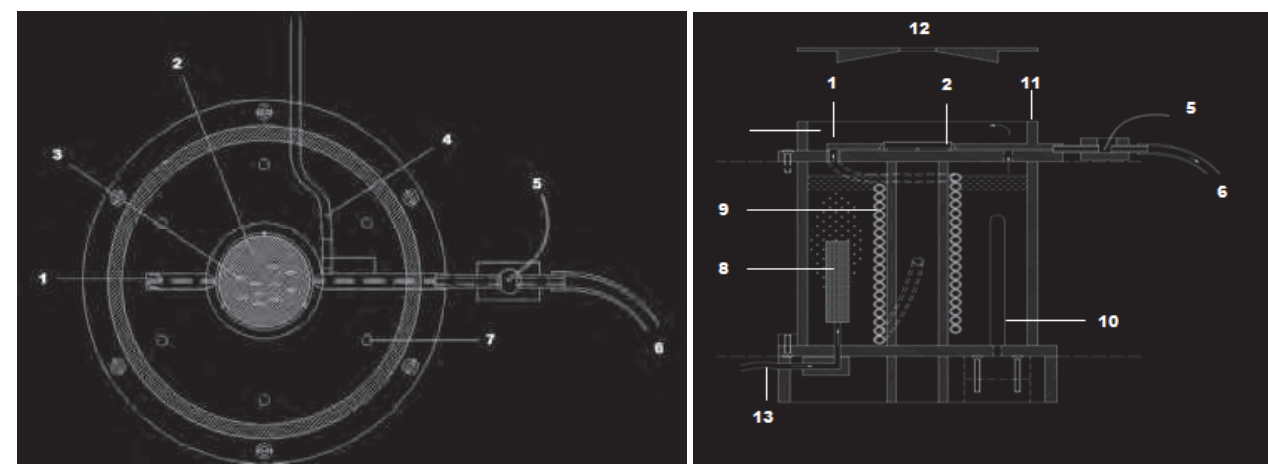

Fig. 1. Interface chamber. Schematic diagram of the interface chamber. (left) superior view (right) lateral view. (1) perfusion solution entry; (2) Millipore membrane; (3) brain slices; (4) thermometer; (5) ground wire; (6) solution output; (7) holes for conduct the warm and moisturized carbogen into the chamber; (8) carbogen bubbler; (9) heating the perfusion solution; (10) heater; (11) chamber external cylinder; (12) carbogen release; (13) carbogen input. 
The heating module is composed of four heating points and two bubblers that disperse carbogen in the water. The equipment, computer controlled, is capable of maintaining the temperature around $34^{\circ} \mathrm{C}$. The water in the bath warms the perfusion solution when it flows through the tube, around the central cylinder.

To monitor regions of the slices where the activities spontaneously emerge and to guide the electrode positioning and also to evaluate the extension of the recruitment, the slices were transilluminated from below using a halogen lamp from the illuminating system of the upright binocular microscope (model SMZ 1500 - Nikon, Japan). The slices were viewed from above through a $3 \times$ or $4 \times$ objective, depending on the size of the region studied. The video images were captured using a CCD camera (Cool SNAP-Pro of 1.4 megapixel cooled, USA). The images were processed on-line for composing the STF images. For this purpose the frames were digitalized by means of a frame-grabber board (DC10 Plus, Pinnacle, USA), controlled by an acquisition software developed in MatLab platform. All the images were captured at a rate of 30 frames per second. Optionally, the images can be processed offline. In this case, all captured frames were stored on a DVD disc. The electrographic signal was used to control the range of frames to be captured.

To obtain images of the light transmittance changes (LTC), the calculation was carried out similarly to the method described by Andrew et al. (1996). Briefly, the averages of the corresponding pixels of the first 50 frames, before the wave propagation, formed the control image $\left(\mathrm{T}_{\text {cont }}\right)$, which was subtracted, pixel by pixel, from each subsequent experimental image $\left(\mathrm{T}_{\text {exp }}\right)$. The resultant image of this subtraction was divided, pixel by pixel, by the $\mathrm{T}_{\text {cont }}$. Specifically

$$
\text { LTC }=\frac{\left(T_{\text {exp }}-T_{\text {cont }}\right)}{T_{\text {cont }}}
$$

Using a gray intensity scale, the series of LTC images revealed areas of the slice where the light transmittance changes with time. To condense on a single image the spatiotemporal features (STF) of paroxysmal activity, the contour of the layer involved in the activity is resembled by a polygonal, drawn manually, by setting pixel positions that are then linked forming the polygonal (Figure 2.A).

The STF images were built column by column. For each LTC image, the average intensity of the pixels of a square region $(21 \times 21$ pixels) centered in each pixel of the polygonal was calculated. These values are the intensities of each pixel of the column obtained rectifying the polygonal over a vertical line. The STF image is composed disposing these columns, from left to right, following the temporal sequence (Figure 2.B and 2.C).

\subsubsection{Electrophysiological and spatial characteristics}

Electrographically, the non-synaptic epileptiform activity, recorded in the extracellular space of the granular layer of the dentate gyrus, is characterized by ictogenic period with intense population spikes bursts with amplitudes around $10 \mathrm{mV}$, duration between $30-60 \mathrm{~s}$ and interevent interval around 50s (Fig. 3). These bursts are always accompanied by a negative DC-shift $(5-10 \mathrm{mV})$. Concurrently to the electrographic manifestations, the optical images show that the spatial recruitment engages a portion of the granular layer, preferably the infra-piramidal portion. Although it is possible to estimate with two electrodes the velocity of propagation of the events in the order of $\mathrm{mm} / \mathrm{s}$, it is not unusual to observe the 


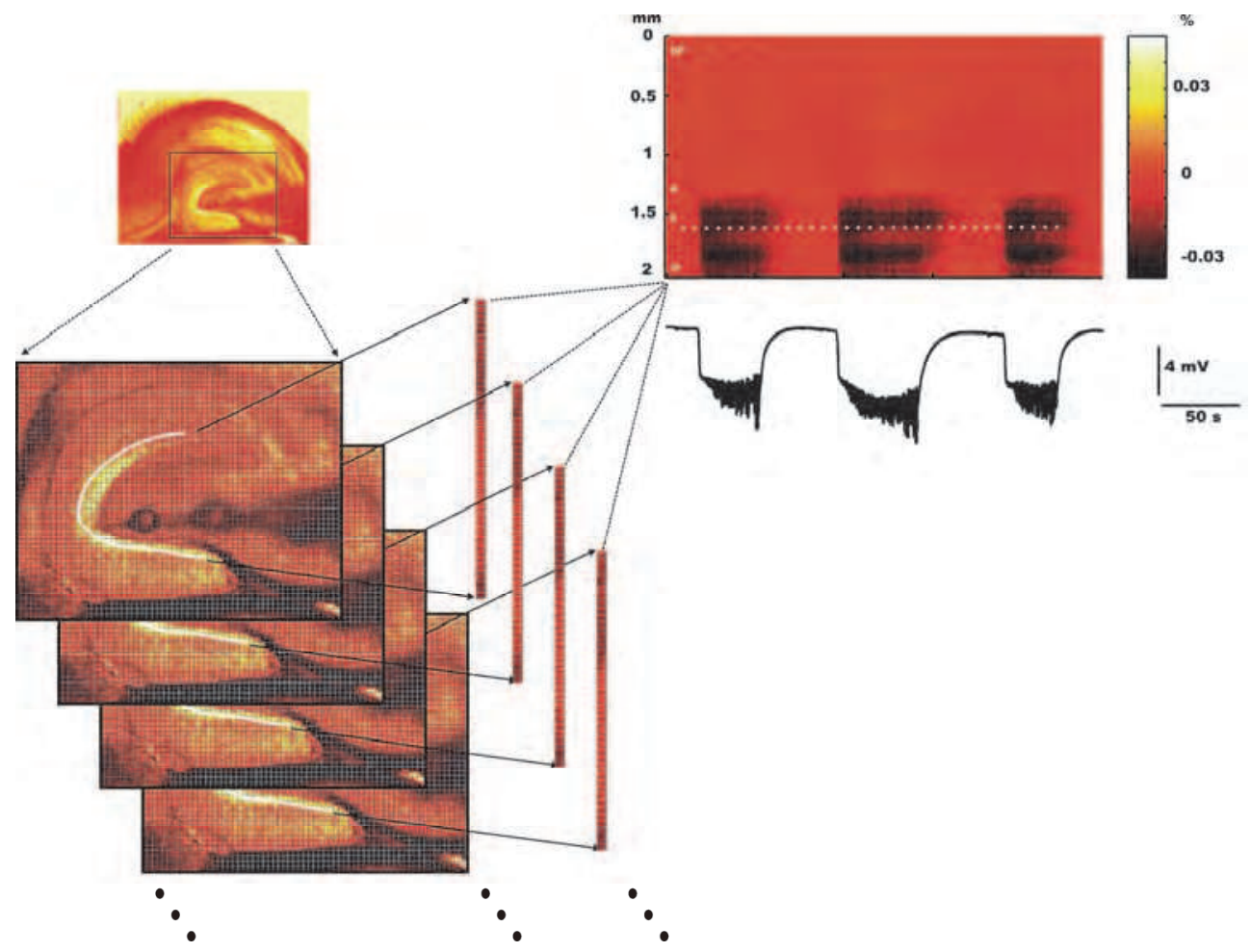

Fig. 2. Schematic representation of the procedure for composing the STF images. (A) The brain slice and the polygonal representing the contour of the layer of interest. (B) Temporal sequence of frames showing the rectified polygonal extracted from each of them. (C)

Disposing each polygonal rectified and side by side, the STF images are composed and the pixels are calculated according to the equation 1 . The scale indicates the percentage of the light transmittance change according to equation (1).

simultaneous build up of the whole neuronal region recruited, identified by no delays between the signals, suggesting a synergistic excitation of the neuronal tissue involved (Fig 2) The paroxysmal activity sustains stable for up to 3-4h after $\mathrm{Ca}^{2+}$ washout has begun. In our experiments, spreading depression usually appears spontaneously after this period. This occurrence of a few episodes of spreading depression normally precedes the irreversible deterioration of the preparation (Fig. 3).

In a substantial portion of the slices investigated in our laboratory, the increase of the DC shift can be associated with a decrease of the population spikes amplitude. This observation, when correlated with the optical signal, shows that it is not always valid to inspect synchrony by means of evaluating the population spikes amplitudes. In fact, as exemplified in Fig. 4, the eugenol effect, a blocker of sodium voltage-sensitive channel, is the reduction of the neuronal population recruited, accompanied by increase of the population spike amplitudes and decrease of the DC shift amplitude. Correlating this observation with the biophysical mechanisms of the bursts generation, analyzed in session 5.2, it can be proposed that the population spike amplitude can also be modulated by the transmembrane ionic 
gradients. These gradients, when involving a large neuronal population, may change significantly resulting the decrease of the action potentials amplitude and, therefore, of the population spikes. In these circumstances, the association with synchronism decrease doesn't make sense.
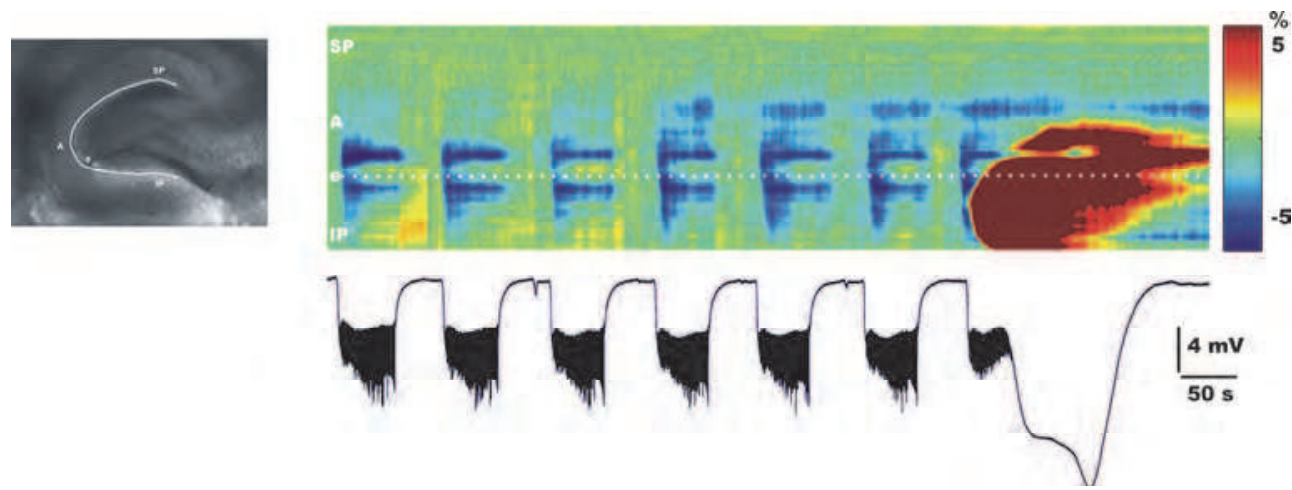

Fig. 3. STF image of a sequential nonsynaptic bursts and the transition to spreading depression. Simultaneous extracellular potential is shown in the bottom. The scale indicates the percentage of the light transmittance change according to equation (1).

(A)

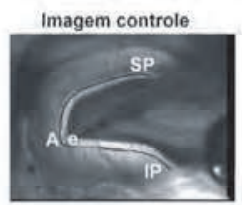

(B)

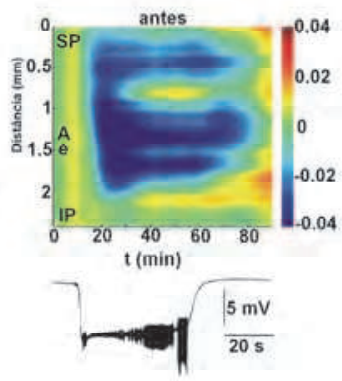

(C)

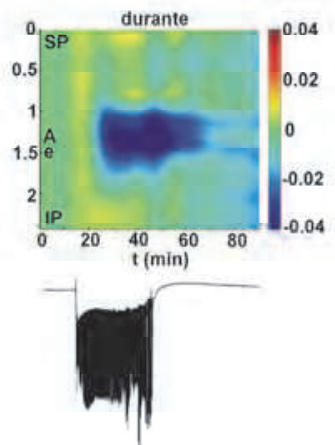

(D)

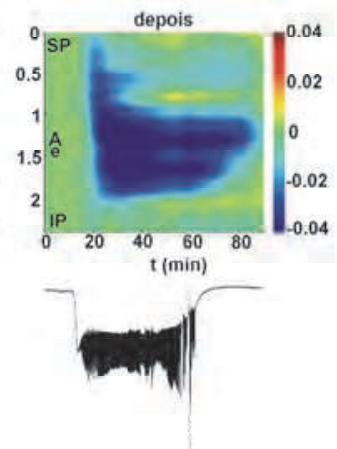

Fig. 4. Optical image and extracellular potential measured simulataneously. (A) Hippocampus slice magnified to show details of the dentate gyrus ( A: apex; SP: suprapiramidal; IP: infrapiramidal ). Along of the granular layer, the poligonal line used to extract the STF images shown in (B - before eugenol), (C - during eugenol) and (D - after eugenol).

\section{Nonsynaptic mechanisms}

The processes of neuronal depolarization and hyperpolarization can not be described simply by $\mathrm{Na}^{+}$channels and voltage-sensitive $\mathrm{K}^{+}$or by the movement of $\mathrm{Na}^{+}, \mathrm{K}+{ }^{+} \mathrm{Cl}^{-}$ associated with the activation of neurotransmitter receptors. In fact, for processes that 
involve the activation of populations of neurons and glial cells synchronously, such as epileptiform activity, in particular those of origin not only synaptic, ionic balance is also determined by the activity of a large number of pumps, exchangers and cotransporters. The net effect of the performance of these mechanisms is therefore critical to cellular excitability. It is important to observe that ion flux associated with transporter molecules is electrically neutral and is mediated by ionic gradients established primarily by $\mathrm{Na} / \mathrm{K}$ pump. Therefore, as pointed out by Schwartzkroin at al. (1998), the identification of the nonsynaptic mechanisms participating on this dynamic process and their location (e.g. neuron versus glia) is critical to our understanding of excitability controls. In this item, we will describe the nonsynaptic mechanisms whose actions on the epileptiform activity will be considered in our investigation.

\section{$3.1 \mathrm{Na} / \mathrm{K}$ pump}

The pumping process mediated by the $\mathrm{Na} / \mathrm{K}$ pump is an ionic transport mechanism responsible for maintaining the $\mathrm{Na}^{+}$and $\mathrm{K}^{+}$transmembrane concentration gradients, essentials for several cellular functions. The $\mathrm{Na} / \mathrm{K}$ pump promotes the coupled $\mathrm{Na}^{+}$efflux and $\mathrm{K}^{+}$influx, in a 3:2 rate and using the energy liberated by the ATP hydrolyses (Glitsch, 2001). Nowadays, the functioning of the $\mathrm{Na} / \mathrm{K}$ pump in terms of the Albers-Post alternating gate model (Scheiner-Bobis, 2002; Horisberger, 2004) is very well accepted. The Na/K pump is conceived as ionic channel with two gates, one external and other internal. The opening and closing of these gates are coupled and controlled by phosphorylation and dephosphorylation of the $\mathrm{Na} / \mathrm{K}$-ATPase, occurring alternately and promoting the transport of $\mathrm{Na}^{+}$to the extra- and $\mathrm{K}^{+}$to the intracellular space.

\subsection{Cation-chloride co-transporter and exchanger mechanisms}

Investigations from hippocampal slices in vitro show that cation chloride cotransporter antagonists block epileptiform activity in a variety of seizure models, regardless of the synaptic mechanisms involved. For example, furosemide blocked epileptiform activity in the zero-calcium model in which all chemical synaptic activities are absent, and in which epileptiform discharges must be fully mediated by mechanisms other than chemical synapses. Other in vitro studies showed that furosemide decreases the cellular swelling during conditions of increased $\left[\mathrm{K}^{+}\right]_{\mathrm{o}}$ and blocks ECS decreases in hippocampal slices during stimulation-evoked discharges and epileptiform activity. These results show that the cationchloride antagonists affect some mechanisms common to all seizure models tested, including those that are not dependent on chemical synaptic interactions, and therefore, are required for maintenance of epileptiform activity.

At the start of investigations into the cotransporter it was difficult to differentiate one type of cation-chloride cotransporter (CCC) from the other. However, it is currently known that the CCC family in mammals consists of nine members encoded by the genes Slc12a1-9. Two members are Na-K-2Cl cotransporters (NKCCs; isoforms NKCC1 and KCC2), one is an Na$\mathrm{Cl}$ cotransporter (NCC), and four are $\mathrm{K}-\mathrm{Cl}$ cotransporters (KCCs; isoforms $\mathrm{KCC} 1-4)$. The physiological roles of the remaining two CCCs (CIP1 or Slc12a8, and CCC9 or Slc12a9) are yet unknown. With the exception of NKCC2 and NCC, which are predominantly found in kidney, all CCCs are expressed in neurons or glial cells - or both - at least at some stage of CNS development. For all CCCs members, the Na-K ATPase generates plasmalemmal $\mathrm{K}^{+}$ and $\mathrm{Na}^{+}$gradients that provide the main source of energy for their function. The transport 
stoichiometry of CCCs renders them electrically silent, thus they do not directly influence the neuronal membrane potential (Blaesse et al., 2009).

The NKCC has the following characteristics (Russell, 2000): 1) displacement of ions through the NKCC requires that all three ionic species $\left(\mathrm{Na}^{+}, \mathrm{K}^{+}\right.$and $\left.\mathrm{Cl}-\right)$ are simultaneously present in a same face of the membrane, 2) furosemide and congeners bind to proteins co-carrier and inhibit the transport of the three ions; 3 ) under normal ionic conditions, it functions with the influx of ions and the process has a stoichiometry of $1\left(\mathrm{Na}^{+}\right): 1\left(\mathrm{~K}^{+}\right): 2\left(\mathrm{Cl}^{-}\right)$for the majority of cells. However, during epileptiform events, which occur in large influxes of $\mathrm{Na}^{+}$ and $\mathrm{Cl}^{-}$, the direction of flow can reverse $\mathrm{NKCC}$, therefore carrying the ions to the extracellular environment. The magnitude and direction of ion flux mediated by the NKCC, described by Geck and Pfieffer (1985), are functionally proportional to the difference between the products of concentrations.

Similar to NKCC, the KCC is characterized by a cotransporter protein that mediates the movement of ions, obligatorily coupled in the same direction (in this case, $\mathrm{K}^{+}$and $\mathrm{Cl}^{-}$). The direction of flow depends on the concentration gradients of the two ions across the membrane. Thus, under normal conditions, the KCC promotes the efflux of ions $\mathrm{K}^{+}$and $\mathrm{Cl}^{-}$. The KCC is also blocked by the diuretic furosemide and its congeners, but with less efficiency. In most cells where the KCC has been found, their main function seems to be the regulation of cell volume by removal of $\mathrm{K}^{+}$ions and the $\mathrm{Cl}^{-}$intracellularly. As with the $\mathrm{NKCC}$, the KCC flow is functionally proportional to the difference between the products of ions concentrations (Hochman et al., 1999).

Another type of ion transporter similar to the cotransporter mechanisms is the exchangers. These transporters activity constitutes an electroneutral transport based on the simultaneous exchange of a pair of anions or cations. These mechanisms are present in the hippocampus and their functions are associated with transmembrane ionic gradient recovery, cell volume regulation, and $\mathrm{pH}$ (Chesler, 2003). The exchangers under investigation in our group are $\mathrm{Na}^{+} / \mathrm{H}^{+}$and $\mathrm{HCO}_{3}{ }^{-} / \mathrm{Cl}^{-}$. The last exchanger is considered to have, in each side, sites whose affinities are exclusive to the ions involved. However, for the $\mathrm{Na}^{+} / \mathrm{H}^{+}$exchanger, there are evidences of different behaviour; the enzyme is known to have also affinity to $\mathrm{K}^{+}$(Sychrova, 2004).

\subsection{Osmotic regulation and cell volume changes}

Investigating the effect of osmolarity on synchronized neuronal activities supported by nonsynaptic mechanisms, Dudek et al. (1990) found that decreasing the extracellular osmolarity, which reduces extracellular volume, the epileptiform bursts become more intense. Additionally, the increase in osmolality with solutes which do not permeate the cell membranes, causing an increase in extracellular volume, ends up blocking or lowering epileptiform discharges. Therefore, reductions in extracellular volume can enhance the synchronization between hippocampal CA1 neurons mediated by non-synaptic communications. Indeed, while changes in the volume of the extracellular space (ECS) are small during normal physiological activity, during synchronized excitatory activity, such as bursts of epileptiform discharges, such variations can be considerable. Specifically in the case of non-synaptic epileptiform activity, the consequence of these changes in ECS can be: (i) effect of extracellular ion accumulation would be magnified due to the reduced level of dilution (ii) ephaptic interactions, mediated by current flow through ECS, would increase due to the high resistance of the ECS. 


\subsection{Membrane ionic currents}

The main ionic species involved in the nonsynaptic paroxysms are sodium, potassium and chloride. These ions flow through the neuronal and glial membranes. During the excitation process of the nonsynaptic bursts their actuations, therefore, are not related with the neurotransmission through the synaptic cleft. The permeability changes of each ionic specie through the corresponding channels are responsible for the changes in the intracellular potential. The ionic channel types considered in the present investigation were: sodium and potassium voltage dependent channels, persistent sodium channels, A-type potassium channel, chloride channel (with constant permeability), chloride channel voltage channel, sodium, potassium and chloride fluxes through gap junctions, sodium, potassium and chloride channels with constant permeability (Fig. 5)

\section{Nonsynaptic connections}

The types of nonsynaptic interactions that may be involved in the synchronization include: electrotonic interactions mediated by gap-junctions (Naus et al., 1991; Perez-Velazques et al., 1994), changes in extracellular space (Roper et al., 1992), field effects (Jefferys \& Haas, 1982; Taylor \& Dudek, 1982; Dudek et al., 1986), and extracellular ionic fluctuations (Taylor \& Dudek, 1984). In the hippocampus, especially in the DG, the tight packing of the cell bodies of neurons and glial cells constitutes an adequate substrate for the nonsynaptic connections. In high-potassium and zero- $\mathrm{Ca}^{2+}$ conditions the granule cells have some endogenous bursting capabilities able to sustain synchronization and, consequently, spontaneous epileptiform activity (Pan \& Stringer, 1996). As these observations have been made in the absence of synaptic transmission, because $\mathrm{Ca}^{2+}$ has been deleted from the bath solution, synchronization mechanisms must have nonsynaptic origin (Schweitzer et al., 1992; Pan \& Stringer, 1996) and could be mediated, as already mentioned, by gap-junctions, ionic fluctuations, or field effect (Fig. 6)

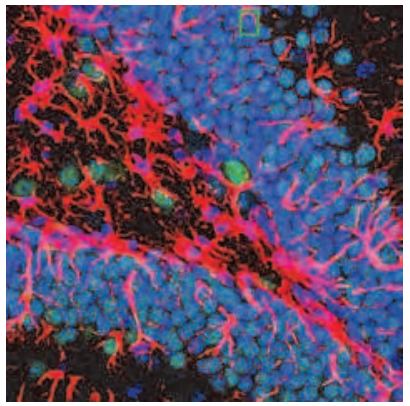

(A)

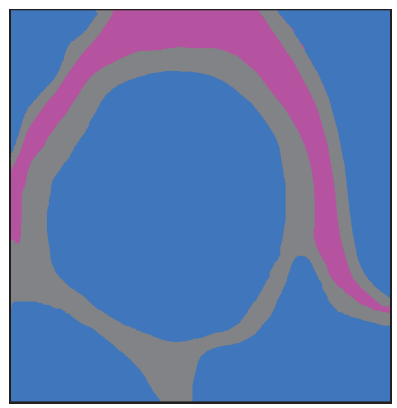

(B)

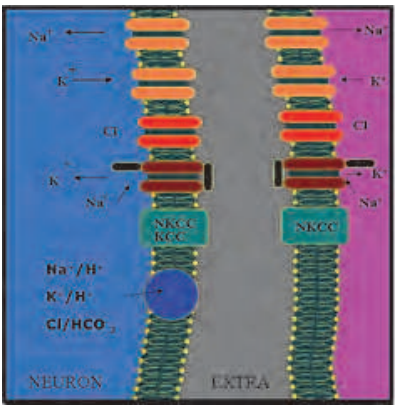

(C)

Fig. 5. Diagramatic conception of the tissue and its cell membranes component representation. (A) DG granullar layer - neurons (blue/green) in the dendate gyrus surrounded by astrocytic processes (red) (extracted from J. Breunig, Rakic Lab.) allows to extract the basic constituents. From the squared region in (A) and magnified in (B), it can be defined the functional unit of the tissue. From this functional unit an additional magnification $(\mathrm{C})$ allow to define the main components of the neuronal and glial membranes. $\mathrm{Na}^{+}$(orange), $\mathrm{K}^{+}$(orange) and $\mathrm{Cl}^{-}$(red) channels, $\mathrm{Na} / \mathrm{K}$ pumps (brown), cotransporters (green) and exchangers (blue). 


\section{Biophysical aspects of the nonsynaptic epileptiform activities}

The complexity of the mechanisms involved in the nonsynaptic epileptiform activities comprehend a puzzle where the collection of experimental data is not enough to unravel the biophysical aspects of the initiation, the build up, and the termination of these activities. In other words, the main mechanisms responsible for the transition from the interictal to the ictal state must be explored by means of a methodology able to translate all experimental observations in a single systemic representation of the neuronal tissue that is the source of the activity. In this section, we show the mathematical description of subcellular mechanisms suspected to have significant involvement in the non-synaptic epileptiform activity. Next, neurons and glial cells are represented by the composition of these mechanisms. Finally, with population of neurons and glial cells, nonsynaptically connected, the neuronal tissue is represented and the epileptiform activities can be computationally simulated. With the simulations, the mechanisms are manipulated allowing investigating their contributions.

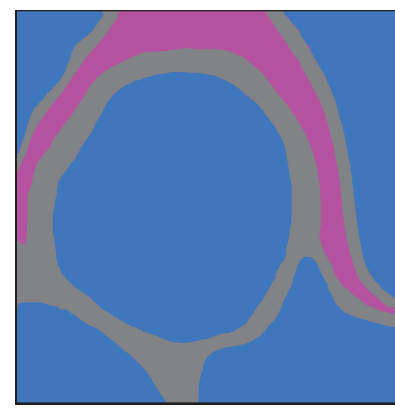

(A)

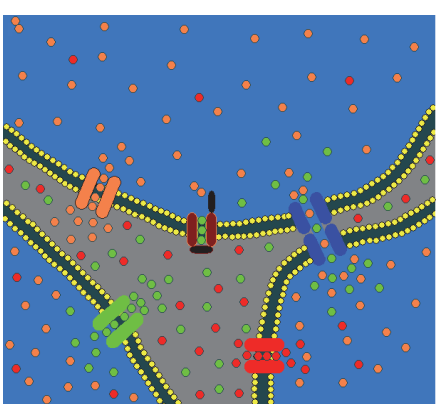

(B)

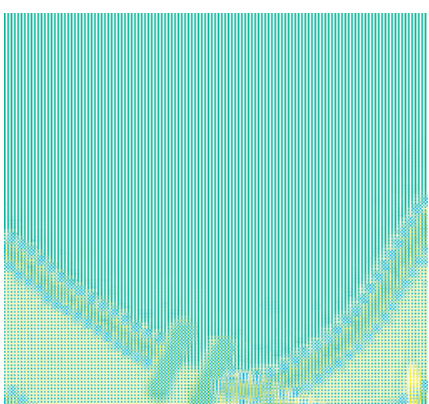

(C)

Fig. 6. Nonsynaptic connections can be seen magnifing the squared region of the functional unit represented in (A). In (B), the ionic flow through ionic channels (green, red and blue), pumps (brown), cotransporters and exchangers (not shown) results extracellular ionic concentration changes which consists a nonsynaptic connection. The gap-junctions are the second type of nonsynaptc connections which also is responsible for the mutual coumpling between neurons. In $(C)$, the third type of nonsynaptic connectons, the eletric field effect. The electric field generated by the ionic currents trough a given cell membrane is able to interfere with the intracellular potential of the immediate vicinity cells.

\subsection{Modelling the dentate gyrus}

\subsubsection{Geometric representation of the cell body layer}

The cell body layer of the DG, characterized by a packing of neurons and glial processes, was represented by a network of functional units. Each functional unit was composed by the cell body of a neuron and a segment of a glial process, as depicted in Fig. 7 (left). The specific geometry of each cell population was not characterized, only the threedimensional (3D) distribution of the functional units, representing the cell body layer, was incorporated. To simulate the experimental maneuver for inducing the nonsynaptic epileptiform activity in the hippocampal slice maintained in an interface chamber, the bathing fluid was represented by two shells of compartments covering the inferior and lateral sides of the cell body layer. The internal shell was composed by compartments with inactive membranes allowing the electrodiffusion of ions through the extracellular space. The most external shell 
was composed by compartments with constant ionic concentrations, representing the relative infinite volume of the bathing fluid in respect to the extracellular volume of each functional unit. The superior face of the cell body layer was not covered and depicted the slice in the liquid/gas interface. As there is no fluidic perfusion at this face, the ionic gradient was null in the orthogonal direction. In Fig. 7 (right), a schematic representation of the interfaces neuron/extracellular/glial cells, with the corresponding mechanisms simulated, is shown.

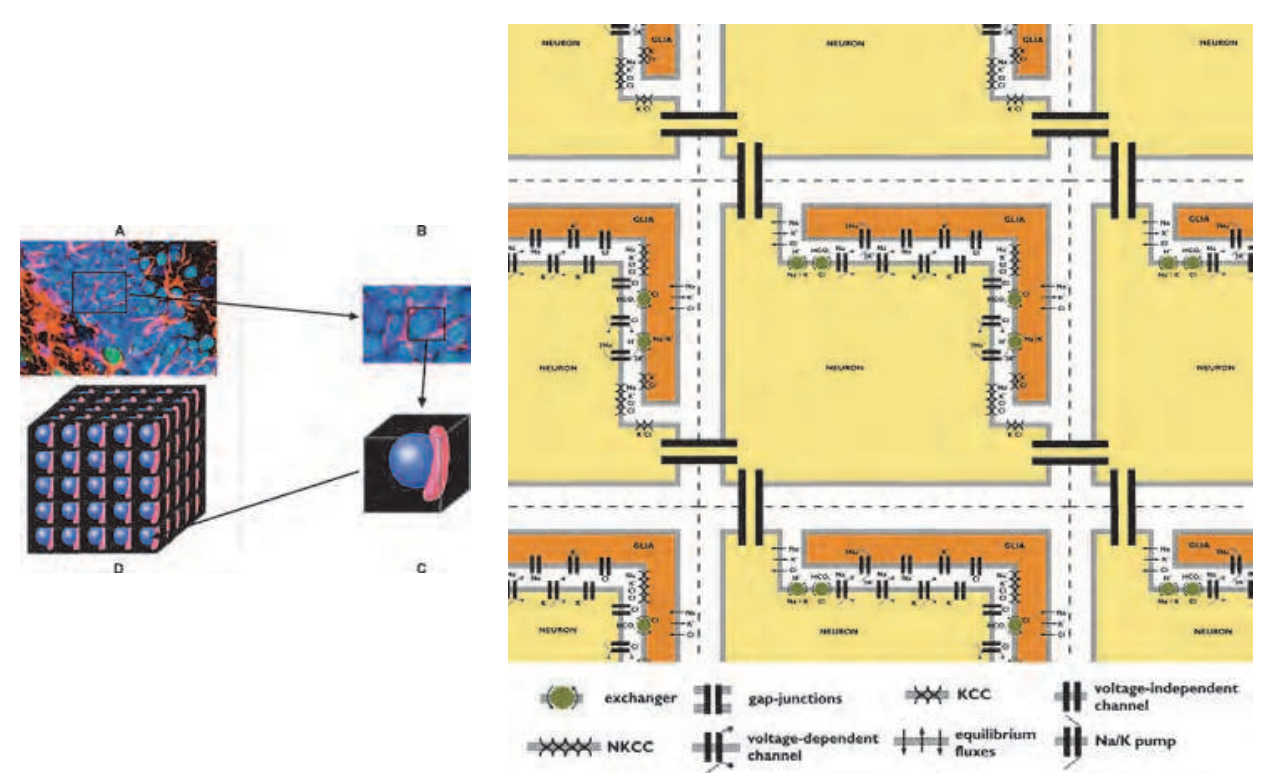

Fig. 7. Left: (A) DG granullar layer - the picture of the neurons (blue/green) in the dentate gyrus surrounded by astrocytic processes (red) (extracted from J. Breunig, Rakic Lab) allows to extract the basic constituents (B) of the functional unit (C), which will form the nodes of the tridimensional computational network used to simulate the DG (D). Right: Schematic representation of the interfaces neuron/extracellular/glial cells with the corresponding mechanisms embedded in the simulated membranes. Each neuron is connected to the neurons of the functional units of the immediate vicinity. The glial cells connection with the vicinity is mediated exclusively by the extracellular space. Modified from Almeida et al (2008).

\subsubsection{Mathematical description}

The fluxes through the ionic channels, gap-junctions, or $\mathrm{Na} / \mathrm{K}$ pumps were described by GHK current equation (Hille, 1992):

$$
\Phi_{c, \text { type }}^{C E L L}=P_{c, \text { type }} Z_{c} F \frac{V_{k}}{R T} \frac{[C]_{i} e^{\frac{Z_{c} \mathrm{FV}_{k}}{R T}}-[C]_{0}}{e^{\frac{Z_{c} \mathrm{FV}_{k}}{R T}}-1},
$$


where $\phi_{c \text {, type }}$ is the flux of the ion C associated to the type (channel, pump, gap junction) of mechanism described, $\mathrm{P}_{\mathrm{c} \text {,type }}$ is the permeability, $\mathrm{V}_{\mathrm{k}}$ is the transmembrane potential in the case of the ionic channels and the electrogenic current pump. When referring to gapjunctions, $\mathrm{V}_{\mathrm{k}}$ is the potential difference between the neighboring cells connected by the connexins, $[\mathrm{C}]_{\mathrm{i}}$ and $[\mathrm{C}]_{\mathrm{O}}$ are the intracellular and extracellular concentration, respectively. When calculating the gap-junction current, $[\mathrm{C}]_{\mathrm{O}}$ is replaced by the intracellular ionic concentration of the cell connected, $\mathrm{z}_{\mathrm{c}}$ is the valence of the ion $\mathrm{C}, \mathrm{F}(96.487 \mathrm{C} / \mathrm{mmol})$ the Faraday constant, $\mathrm{R}(8.314 \mathrm{mV} . \mathrm{C} / \mathrm{K} . \mathrm{mmol})$ the gas constant and $\mathrm{T}(210.16 \mathrm{~K})$ the temperature.

The permeabilities of the sodium and potassium voltage dependent channels were simulated using the Hodgkin-Huxley formalism (Supplemental Material - Almeida et al., 2008). The ionic permeability parameters $\bar{P}_{N a, \text { fast }}^{\text {neuron }}\left(7.78 \times 10^{-4} \mathrm{~cm} / \mathrm{s}\right), \quad \bar{P}_{K}^{\text {neuron }}\left(1.80 \times 10^{-4} \mathrm{~cm} / \mathrm{s}\right)$, $\bar{P}_{N a, \text { persistent }}^{\text {neuron }}\left(7.20 \times 10^{-8} \mathrm{~cm} / \mathrm{s}\right), \quad \bar{P}_{K, A}^{\text {neuron }}\left(3.60 \times 10^{-4} \mathrm{~cm} / \mathrm{s}\right), \quad P_{C l, \text { const }}^{\text {neeron }}\left(3.60 \times 10^{-6} \mathrm{~cm} / \mathrm{s}\right)$, $\bar{P}_{C l, \text { volt-depend }}^{\text {neuron }}\left(1.08 \times 10^{-5} \mathrm{~cm} / \mathrm{s}\right)$ and $P_{A}^{\text {neuron }}\left(2.04 \times 10^{-3} \mathrm{~cm} / \mathrm{s}\right)$ are the quantitative representation of the population of each mechanism (in this case, channels or pumps) involved. Since these parameters were adjusted to reproduce the activity inductions, they were considered as investigation parameters. This means that these parameters were adjusted heuristically aiming at reproducing the activities, as well as investigating the preponderance of each mechanism for generating the events and their characteristics, always respecting the experimental observations. These experimental observations were collected from experiments carried out in our laboratory or from published data, like Xiong and Stringer (2000) and Pan and Stringer (1996). Based on this inspection, the associations observed between each parameters and their influences on the activities are, basically: i) $\bar{P}_{\mathrm{Na} \text {, fast }}^{\text {neuron }}$ - depolarizing phase of the action potential; ii) $\bar{P}_{K}^{\text {neuron }}$ - polarizing phase of the action potential, neuronal excitability and extracellular potassium accumulation; iii) $\bar{P}_{N a \text {,persistent }}^{\text {neuron }}$ - initial cell depolarization (preceding the action potential firing), neuronal excitability and action potential frequency; iv) $\bar{P}_{K, A}^{\text {neuron }}$ - action potential frequency; v) $P_{C l, \text { const }}^{\text {neuron }}$ and $\bar{P}_{C l \text {,volt-depend }}^{\text {neuron }}$ - neuronal resting potential and extracellular chloride concentration; vi) $P_{A}^{\text {neuron }}-\mathrm{Na} / \mathrm{K}$ pump activity.

The parameters $P_{g, N a}\left(6.73 \times 10^{-8} \mathrm{~cm} / \mathrm{s}\right), P_{g j, K}\left(9.92 \times 10^{-8} \mathrm{~cm} / \mathrm{s}\right)$ and $P_{g j, C l}\left(1.84 \times 10^{-8} \mathrm{~cm} / \mathrm{s}\right)$ represent the intercellular permeability through the gap-junctions. The adjustment of these parameter was guided by the experiments from MacVicar and Dudek (1982). The permeability parameters for the glial cells, $\mathrm{P}_{\mathrm{Na}}$ glia $\left(1.00 \times 10^{-8} \mathrm{~cm} / \mathrm{s}\right), \mathrm{P}_{\mathrm{K}^{\text {glia }}}\left(1.08 \times 10^{-7} \mathrm{~cm} / \mathrm{s}\right)$ and $\mathrm{P}_{\mathrm{Cl}^{\mathrm{g}}}$ glia $\left(2.50 \times 10^{-8} \mathrm{~cm} / \mathrm{s}\right)$, were adjusted aiming at reproducing the resting potential typical for these cells (Pan \& Stringer, 1996). The Na/K pump parameter, $\mathrm{P}_{\mathrm{A}}$ glia $(2.04 \times$ $10^{-2} \mathrm{~cm} / \mathrm{s}$ ), was tuned to control the $\left[\mathrm{Na}^{+}\right]_{i}$ of the glial cells and also to contribute to controlling the $\left[\mathrm{K}^{+}\right]_{\mathrm{o}}$ during the epileptiform events. The activation and inactivation factors values $\left(\mathrm{m}_{\text {fast }}=0.03, \mathrm{~h}_{\text {fast }}=0.78, \mathrm{n}=0.1, \mathrm{w}_{\text {pers }}=0.0003, \mathrm{a}_{\mathrm{A}}=0.1, \mathrm{~b}_{\mathrm{A}}=0.8\right)$ of the voltage dependent channels correspond to the resting state defined before the activities induction.

The sodium potassium ATPase function was modeled considering the main reactions involved, always following the Albers-Post model (Heyse et al., 1994; Rodrigues et al., 2008). From the reactions describing the Albers-Post cycles, two reactions were derived, one for the forward cycle, $3 \mathrm{NaiEi}+2 \mathrm{KoEo}+\mathrm{ATPEi} \leftrightarrow \mathrm{Ai}$, and other for the reverse cycle, $3 \mathrm{NaoEo}+2 \mathrm{KiEi}+\mathrm{ADPEi}+\mathrm{PEi} \leftrightarrow \mathrm{Ao}$. 
The reactions predict the formation of a fictitious ion $\mathrm{A}+$, product of each exchange of $3 \mathrm{Na}+$ by $2 \mathrm{~K}+$, in the intra- or extracellular space, depending on the cycle direction. The reactions from the Albers-Post model were used to predict the substates formation and to deduce equations for the intra- and extracellular concentrations of the ion $\mathrm{A}+$ :

$\left[\mathrm{A}^{+}\right]_{i}=\mathrm{K}_{\mathrm{A}}^{\mathrm{i}} \mathrm{C}_{\mathrm{E}_{\mathrm{Na}, \mathrm{K}}}^{\text {m,total }}\left(\frac{[\mathrm{ATP}]_{\mathrm{i}}}{[\mathrm{ATP}]_{\mathrm{i}}+\mathrm{K}_{\mathrm{ATP}}^{\mathrm{i}}\left(1+\frac{[\mathrm{ADP}]_{\mathrm{i}} \mathrm{C}_{\mathrm{P}}^{\mathrm{i}}}{\mathrm{K}_{\mathrm{ADP}, \mathrm{P}}^{\mathrm{i}}}\right)}\right)\left(\frac{\left[\mathrm{Na}^{+}\right]_{i}}{\left[\mathrm{Na}^{+}\right]_{i}+\mathrm{K}_{\mathrm{Na}, \text { pump }}^{\mathrm{i}}\left(1+\frac{\left[\mathrm{K}^{+}\right]_{i}}{\mathrm{~K}_{\mathrm{K}, \text { pump }}^{\mathrm{i}}}\right)}\right)^{3}\left(\frac{\left[\mathrm{K}^{+}\right]_{o}}{\left[\mathrm{~K}^{+}\right]_{o}+\mathrm{K}_{\mathrm{K} \text {,pump }}^{\mathrm{o}}\left(1+\frac{\left[\mathrm{Na}^{+}\right]_{o}}{\mathrm{~K}_{\mathrm{Na}, \text { pump }}^{\mathrm{o}}}\right)}\right)^{2}$

$\left[\mathrm{A}^{+}\right]_{o}=\mathrm{K}_{\mathrm{A}}^{\mathrm{o}} \mathrm{C}_{\mathrm{E}_{\mathrm{Na}, \mathrm{K}}}^{\mathrm{m}, \text { total }}\left(\frac{[\mathrm{ADP}]_{\mathrm{i}}[P]_{i}}{[\mathrm{ADP}]_{\mathrm{i}}[P]_{i}+\mathrm{K}_{\mathrm{ADP}, \mathrm{P}}^{\mathrm{i}}\left(1+\frac{[\mathrm{ATP}]_{\mathrm{i}}}{\mathrm{K}_{\mathrm{ATP}}^{\mathrm{i}}}\right)}\right)\left(\frac{\left[\mathrm{Na}^{+}\right]_{o}}{\left[\mathrm{Na}^{+}\right]_{o}+\mathrm{K}_{\mathrm{Na}, \text { pump }}^{\mathrm{o}}\left(1+\frac{\left[\mathrm{K}^{+}\right]_{o}}{\mathrm{~K}_{\mathrm{K}, \text { pump }}^{\mathrm{o}}}\right)}\right)^{3}\left(\frac{\left[\mathrm{K}^{+}\right]_{i}}{\left[\mathrm{~K}^{+}\right]_{i}+\mathrm{K}_{\mathrm{K}, \text { pump }}^{\mathrm{i}}\left(1+\frac{\left[\mathrm{Na}^{+}\right]_{i}}{\mathrm{~K}_{\mathrm{Na}, \text { pump }}^{\mathrm{i}}}\right)}\right)^{2}$

The investigations carried on by Nakao and Gadsby (1989) about the Na/K pump activity dependence on the extracellular concentrations of $\mathrm{Na}^{+}$and $\mathrm{K}^{+}$allowed to guide the pump parameters adjustment. During the experiments, [ADP] was kept constant and equal to 0 $\mathrm{mM}$ and a $\mathrm{Na}^{+}$-free solution was used as extracellular medium. Therefore, normalizing the current in terms of the current for $\left[\mathrm{K}^{+}\right]_{\mathrm{o}}=5.4 \mathrm{mM}$, from equation 2 , the following equation could be derived:

$$
\Phi_{A^{P}, \text { pump }}^{\text {norm }}=\left(\frac{\left[K^{+}\right]_{o}}{\left[K^{+}\right]_{o}+K_{K}^{o}}\right)^{2} /\left(\frac{5,4}{5,4+K_{K}^{o}}\right)^{2},
$$

where $\Phi_{\text {Ap,pump }}$ norm is the normalized pump current. Using this equation to fit a curve to the experimental data, $K_{K^{0}}$ was estimated $\left(K_{K^{0}}=0.094 \mathrm{mM}\right)$. Once this constant was determined, considering the experimental conditions described by the authors, $\left[\mathrm{Na}^{+}\right]_{\mathrm{o}}=150 \mathrm{mM}$ and $\mathrm{V}_{\mathrm{m}}=0 \mathrm{mV}$, and with the previous value determined for $K_{\mathrm{K}^{\circ}}, K_{\mathrm{Na}}{ }^{o}$ could be calculated finding the best curve fitting to the data, using the following equation, which gave $K_{N a^{o}}=34,7 \mathrm{mM}$.

$$
\Phi_{A^{P}, \text { pump }}^{\text {norm }}=\left(\frac{\left[K^{+}\right]_{o}}{\left[K^{+}\right]_{o}+K_{K}^{o}\left(1+\frac{150}{K_{N a}^{o}}\right)}\right)^{2} /\left(\frac{5,4}{5,4+K_{K}^{o}\left(1+\frac{150}{K_{N a}^{o}}\right)}\right)^{2},
$$

The intracellular sodium dissociation constant, $K_{N a}{ }^{i}$, was adjusted using the data from Barmashenko et al. (1999). These authors measured the $\mathrm{Na} / \mathrm{K}$ pump current in relation to the intracellular $\mathrm{Na}^{+}$. The cells used in the investigation were kept in $\mathrm{K}^{+}$-free solution and the transmembrane potential was clamped in $0 \mathrm{mV}$. The normalized current (normalization with respect to $\left[\mathrm{Na}^{+}\right]_{i}=50 \mathrm{mM}$ ) could then be described using the next equation. By a curve fitting to the experimental data, $K_{N a}{ }^{i}$ was estimated equal to $0.856 \mathrm{mM}$. 


$$
\Phi_{A^{+}, \text {pump }}^{\text {norm }}=\left(\frac{\left[N a^{+}\right]_{i}}{\left[N a^{+}\right]_{i}+K_{N a}^{i}}\right)^{3} /\left(\frac{50}{50+K_{N a}^{i}}\right)^{3}
$$

Hansen et al. (2002) measured the $\mathrm{Na} / \mathrm{K}$ pump activation with respect to intracellular $\mathrm{Na}^{+}$in the presence of intracellular $\mathrm{K}^{+}(80 \mathrm{mM})$. The experiments were conducted with intra and extracellular ADP-free and $\mathrm{Na}^{+}$-free solutions. These conditions gave the following equation for the normalized current:

$$
\Phi_{A^{+}, \text {pump }}^{\text {norm }}=\left(\frac{\left[N a^{+}\right]_{i}}{\left[N a^{+}\right]_{i}+K_{N a}^{i}\left(1+\frac{80}{K_{K}^{i}}\right)}\right)^{3} /\left(\frac{79,8}{79,8+K_{N a}^{i}\left(1+\frac{80}{K_{K}^{i}}\right)}\right)^{3}
$$

Using this equation for the curve fitting to the experimental data, $K_{K}{ }^{i}$ was estimated equal to $4.831 \mathrm{mM}$.

Friedrich et al. (1996) studied the $\mathrm{Na} / \mathrm{K}$ pump dependence on intracellular ATP. The experiments were conducted with ADP-free intracellular medium and the transmembrane potential was clamped in $0 \mathrm{mV}$. The Equation (6), describing the normalized current with respect to current for $[\mathrm{ATP}]=0.204 \mathrm{mM}$, could then be deduced. Using this equation for calculating the best curve fitting to experimental data, the ATP dissociation constant, $K_{A T P}$, was estimated equal to $0.155 \mathrm{mM}$.

$$
\Phi_{A^{+}, \text {pump }}^{\text {norm }}=\left(\frac{[A T P]^{i}}{[A T P]^{i}+K_{A T P}^{i}}\right) /\left(\frac{0,204}{0,204+K_{A T P}^{i}}\right)
$$

The lacking of information about the $\mathrm{Na} / \mathrm{K}$ pump activity with respect to the intracellular $\mathrm{ADP}$ and $\mathrm{P}$, the intracellular dissociation constant of ADP and $\mathrm{P}, K_{A D P, P^{i}}$, was estimated assuming that the formation and consuming rate of ATP are equal. Additionally, this constant must be high enough to reduce the pump rate in the reverse direction, when $\mathrm{Na}^{+}$is transported to the intracellular medium and $\mathrm{K}^{+}$to the extra. To provide these conditions $K_{A D P, P}$ was assumed equal to $5 \mathrm{mM}$.

The ratio between the equilibrium constants $K_{A}{ }^{i}$ and $K_{A}{ }^{o}$, of the $\mathrm{Na} / \mathrm{K}$ pump reactions, could be calculated by means of the reverse potential of the $\mathrm{Na} / \mathrm{K}$ pump. Therefore, the condition of null $\mathrm{Na} / \mathrm{K}$ current gives:

$$
V_{A}^{r e v}=\frac{R T}{F} \ln \frac{\left[A^{+}\right]_{o}}{\left[A^{+}\right]_{i}}
$$

Glistsch (2001) estimated the $\mathrm{Na} / \mathrm{K}$ pump reverse potential equal to $-232 \mathrm{mV}$. Substituting in Equation (10), and taking into account the normal intra and extracellular $\left[\mathrm{Na}^{+}\right]$and $\left[\mathrm{K}^{+}\right]$, and the corresponding dissociation constants, the ratio $\left[\mathrm{A}^{+}\right]_{\mathrm{o}} /\left[\mathrm{A}^{+}\right]_{i}$ can be described in terms of $K_{A^{o}} / K_{A}{ }^{i}$. The convenient substitutions allowed estimating $K_{A^{o}} / K_{A}{ }^{i}$ equal to 0.012 . Since each parameter of this ratio could not be estimated, it was necessary to concentrate parameters: 


$$
P_{A}^{\text {cell }}=\bar{P}_{A}^{\text {cell }} C_{E_{N a, \mathrm{~K}}}^{m, \text { total }} K_{A}^{i}
$$

where $P_{A}^{\text {cell }}$ is a parameter related to the density of the $\mathrm{Na} / \mathrm{K}$ pumps and was considered an investigative parameter and its value was attributed directly simulating the epileptiform activity.

The equations (12) and (13) were derived from reactions describing the KCC enzyme interaction with its ligands. The neuronal and glial KCC co-transporters proportionality constants convey the expression intensity of these enzymes in the cellular membranes. In this case, the constant $Q_{K C C^{n e u r}}\left(4.21 \times 10^{-3} \mu \mathrm{mol} / \mathrm{s.cm}^{2}\right)$ was assumed as an investigative parameter. Therefore, its value was adjusted along the investigation about the $\mathrm{Cl}^{-}$and $\mathrm{K}^{+}$ levels control, during the nonsynaptic epileptiform activities induction. On the other hand, the $Q_{K C C^{\text {lia }}}\left(5.35 \times 10^{-4} \mu \mathrm{mol} / \mathrm{s} . \mathrm{cm}^{2}\right)$ was estimated aiming at controlling the $\left[\mathrm{Cl}^{-}\right]_{\mathrm{i}}$ in the steady state.

$$
\begin{aligned}
& \Phi_{\mathrm{KCC}}= \mathrm{Q}_{\mathrm{KCC}} \frac{\left[\mathrm{K}^{+}\right]_{\mathrm{i}}\left[\mathrm{Cl}^{-}\right]_{\mathrm{i}}}{\left(\left[\mathrm{K}^{+}\right]_{\mathrm{i}}+\mathrm{K}_{\mathrm{K}, \mathrm{KCC}}^{\mathrm{i}}\left(1+\frac{\left[\mathrm{K}^{+}\right]_{\mathrm{o}}}{\mathrm{K}_{\mathrm{K}, \mathrm{KCC}}^{\mathrm{o}}}\right)\left(\left[\mathrm{Cl}^{-}\right]_{\mathrm{i}}+\mathrm{K}_{\mathrm{Cl}, \mathrm{KCC}}^{\mathrm{i}}\left(1+\frac{\left[\mathrm{Cl}^{-}\right]_{\mathrm{o}}}{\mathrm{K}_{\mathrm{Cl}, \mathrm{KCC}}^{\mathrm{o}}}\right)\right)\right.}- \\
&-\frac{\left[\mathrm{K}^{+}\right]_{\mathrm{O}}\left[\mathrm{Cl}^{-}\right]_{\mathrm{O}}}{\left(\left[\mathrm{K}^{+}\right]_{\mathrm{o}}+\mathrm{K}_{\mathrm{K}, \mathrm{KCC}}^{\mathrm{o}}\left(1+\frac{\left[\mathrm{K}^{+}\right]_{\mathrm{i}}}{\mathrm{K}_{\mathrm{K}, \mathrm{KCC}}^{\mathrm{i}}}\right)\left(\left[\mathrm{Cl}^{-}\right]_{\mathrm{o}}+\mathrm{K}_{\mathrm{Cl}, \mathrm{KCC}}^{\mathrm{o}}\left(1+\frac{\left[\mathrm{Cl}^{-}\right]_{\mathrm{i}}}{\left.\mathrm{K}_{\mathrm{Cl}, \mathrm{KCC}}^{\mathrm{i}}\right)}\right)\right.\right.} \\
& \Phi_{\mathrm{NKCC}}=\mathrm{Q}_{\mathrm{NKCC}} \frac{\left[\mathrm{Na}^{+}\right]_{\mathrm{i}}\left[\mathrm{K}^{+}\right]_{i}\left[\mathrm{Cl}^{-}\right]_{i}^{2}-\left[\mathrm{Na}^{+}\right]_{\mathrm{o}}\left[\mathrm{K}^{+}\right]_{\mathrm{o}}\left[\mathrm{Cl}^{-}\right]_{0}^{2}}{\left(\mathrm{~K}_{\mathrm{Na}, \mathrm{NKCC}}+\left[\mathrm{Na}^{+}\right]_{\mathrm{i}}+\left[\mathrm{Na}^{+}\right]_{\mathrm{o}}\right)\left(\mathrm{K}_{\mathrm{K}, \mathrm{NKCC}}+\left[\mathrm{K}^{+}\right]_{i}+\left[\mathrm{K}^{+}\right]_{0}\right)\left(\mathrm{K}_{\mathrm{Cl}}+\left[\mathrm{Cl}^{-}\right]_{i}+\left[\mathrm{Cl}^{-}\right]_{o}\right)^{2}}
\end{aligned}
$$

Payne (1997) measured the $\mathrm{Rb}^{+}$influx by the KCC cotransporters in dependence on the $\left[\mathrm{Rb}^{+}\right]_{\mathrm{o}}$ and $\left[\mathrm{Cl}^{-}\right]_{\mathrm{o}}$. For each variation of $\mathrm{Rb}^{+}$or $\mathrm{Cl}^{-}$, the initial rate of the $\mathrm{Rb}^{+}$influx was measured. Since for the cation-chloride cotransporters the $\mathrm{Rb}^{+}$and $\mathrm{K}^{+}$affinities were undistinguishable, the $\mathrm{K}^{+}$effects on the cotrasnporters could be inferred using $\mathrm{Rb}^{+}$in the investigations. The experiments carried out by Payne (1997), were used to adjust the dissociation constants for $\mathrm{K}^{+}\left(K_{K, K C C}^{o, n e u r}=7.34 \mathrm{mM}\right)$ and $\mathrm{Cl}^{-}\left(K_{C l, K C C}^{o, n e u r}=92.02 \mathrm{mM}\right)$. Considering the corresponding conditions, the following equations were deduced and used to simulate the experimental data from Payne (1997). The first one was obtained considering the $\left[\mathrm{Rb}^{+}\right]_{\mathrm{o}}$ changing and keeping the $[\mathrm{Cl}]_{0}$ constant. The second equation for $\left[\mathrm{Cl}^{-}\right]_{\mathrm{o}}$ changing, keeping $[\mathrm{Rb}-]_{\mathrm{o}}$ constant.

$$
\begin{gathered}
\Phi_{K C C}^{\text {norm }}=\frac{[R b]_{o}}{\left(K_{R b}+[R b]_{o}\right)} / \frac{25}{\left(K_{R b}+25\right)} \\
\Phi_{K C C}^{\text {norm }}=\frac{[C l]_{o}}{\left(K_{C l, K C C}^{o, \text { neur }}+[C l]_{o}\right)} / \frac{144,2}{\left(K_{C l, K C C}^{o, \text { neur }}+144,2\right)}
\end{gathered}
$$


For the neurons, the intracellular dissociation constants for $\mathrm{K}^{+}$and $\mathrm{Cl}^{-}$, in the membrane internal face, respectively $K_{K, K C C}$,neur and $K_{C l, K C C}$, neur were assumed equal to that at the external face. This simplification assumes that the KCC cotransporters are mainly influenced by the $\mathrm{K}^{+}$and $\mathrm{Cl}$ - transmembrane gradients and less by the enzyme affinities.

In the case of $\mathrm{K}^{+}$and $\mathrm{Cl}^{-}$dissociation constants for the glial $\mathrm{KCC}$ cotransporters, $\mathrm{K}_{\mathrm{K}, \mathrm{KCC}}^{\mathrm{i} \text { glia }}$ $(2.3 \mathrm{mM}), K_{C l, K C C}^{i, g l i a}(0.1 \mathrm{mM}), K_{K, K C C}^{o, g l i a}(200 \mathrm{mM})$ and $K_{C l, K C C}^{o, g l i a}(500 \mathrm{mM})$, the parameters were adjusted to maintain the steady state of the intracellular concentrations of the glial cells.

The neuronal and glial proportionality constants of the NKCC cotransporters, $Q_{N K C C}^{\text {neur }}$ $\left(4.72 \times 10^{-3} \mu \mathrm{mol} / \mathrm{s} . c m^{2}\right)$ and $Q_{N K C C}^{\text {glia }}\left(2.80 \times 10^{-2} \mu \mathrm{mol} /{\mathrm{s} . \mathrm{cm}^{2}}^{2}\right)$, were used to represent the expression intensity of the cotransporter enzymes in the cells membrane. Supposing that this expression intensity guides the contribution of the mechanisms to the activities studied, these parameters were considered as investigative parameters. In this sense, they were adjusted aiming at contributing for the intra and extracellular ionic concentrations of $\mathrm{Na}^{+}$, $\mathrm{K}^{+}$and $\mathrm{Cl}^{-}$.

Concerning the NKCC dissociation constants, the values were estimated simulating experimental data. Tas et al. (1987) measured, in rat brain astrocytes, the $\mathrm{Rb}^{+}$influx, promoted by these cotransporters in dependence on the extracellular concentrations of $\mathrm{Na}^{+}$, $\mathrm{K}^{+}$and $\mathrm{Cl}^{-}$. The measurements were carried out for cells incubated in $\mathrm{Na}^{+}$-free solution (A), in $\left[\mathrm{K}^{+}\right]=1 \mathrm{mM}(\mathrm{B})$ and in $\mathrm{Cl}^{-}$-free solution (C). To adjust the parameters, like as with the KCC cotransporters, the $\mathrm{Na}^{+}, \mathrm{K}^{+}$and $\mathrm{Cl}^{-}$intracellular concentrations were admitted null, respectively, in (A), (B) and (C) conditions. The following corresponding equations $(16,17$ and 18) were used to simulate the $\mathrm{Rb}^{+}$influx, $\Phi_{\mathrm{NKCC}}{ }^{\text {norm, }}$, in dependence on the $\mathrm{Na}^{+}, \mathrm{K}^{+}$and $\mathrm{Cl}^{-}$concentrations.

$$
\begin{gathered}
\Phi_{N K C C}^{n o r m}=\frac{\left[N a^{+}\right]_{o}}{\left(K_{N a, N K C C}+\left[N a^{+}\right]_{o}\right)} / \frac{150,4}{\left(K_{N a, N K C C}+150,4\right)} \\
\Phi_{N K C C}^{\text {norm }}=\frac{\left[K^{+}\right]_{o}}{\left(K_{K, N K C C}+\left[K^{+}\right]_{o}\right)} / \frac{39,9}{\left(K_{K, N K C C}+39,9\right)} \\
\Phi_{N K C C}^{n o r m}=\left(\frac{\left[C l^{-}\right]_{o}}{\left(K_{C l, N K C C}+\left[C l^{-}\right]_{0}\right)}\right)^{2} /\left(\frac{153,4}{\left(K_{C l, N K C C}+153,4\right)}\right)^{2}
\end{gathered}
$$

Analogously to $\mathrm{KCC}$, the extracellular dissociation constants for $\mathrm{Na}^{+}, \mathrm{K}^{+}$and $\mathrm{Cl}^{-}$, in the membrane internal face, $K_{N a, N K C C}^{n e u r}(70.0 \mathrm{mM}), K_{K, N K C C}^{\text {neur }}(2.33 \mathrm{mM}), K_{C l, N K C C}^{\text {neur }}(25.0 \mathrm{mM})$, $K_{N a, N K C C}^{\text {glia }}(70.0 \mathrm{mM}), K_{K, N K C C}^{\text {glia }}(2.33 \mathrm{mM})$ and $K_{C l, N K C C}^{\text {glia }}(25.0 \mathrm{mM})$, were assumed equal to their values at the internal face. Therefore, the direction of net movement of $\mathrm{Na}^{+}, \mathrm{K}^{+}$and $\mathrm{Cl}^{-}$ through the cotransporter will be very sensitive $\mathrm{Na}^{+}, \mathrm{K}^{+}$and $\mathrm{Cl}^{-}$transmembrane gradients. The chloride exchangers were implemented in the model aiming at obtaining the internal ionic equilibrium of the cells during the steady state (Equation 19). Therefore the parameters $Q_{\mathrm{HCO}}^{\text {neur }}, \mathrm{Cl}\left(9.81 \times 10^{-5} \mu \mathrm{mol} / \mathrm{s.cm}^{2}\right), \quad Q_{\mathrm{HCO}}^{\text {glia }}\left(3.38 \times 10^{-4} \mu \mathrm{mol} / \mathrm{s.cm}^{2}\right)$, $K_{C l, \text { exch }}^{\text {neur }}(6.00 \mathrm{mM})$ and $K_{C l \text {,exch }}^{\text {glia }}(0.10 \mathrm{mM})$ were considered as equilibrium parameters and were adjusted for the steady state. 


$$
\phi_{\mathrm{Cl}}=Q_{\mathrm{HCO} / \mathrm{CL}} \frac{\left[\mathrm{Cl}^{-}\right]_{i}}{\left[\mathrm{Cl}^{-}\right]_{i}+K_{\mathrm{Cl}-\mathrm{exch}}}
$$

Similarly to the chloride exchangers, the sodium exchangers were also included to obtain the internal ionic equilibrium of the cells during the steady state (Equation 20). For the same

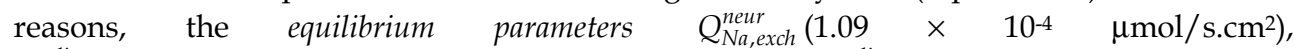
$Q_{\mathrm{Na}, \text { exch }}^{\text {glia }}\left(7.94 \times 10^{-4} \mu \mathrm{mol} / \mathrm{s.cm}^{2}\right), K_{\mathrm{Na}, \text { exch }}^{\text {neer }}(10.0 \mathrm{mM})$ and $K_{\mathrm{Na}, \text { exch }}^{\text {glia }}(13.0 \mathrm{mM})$ were adjusted for the steady state. According to Sychrová (2004), $\mathrm{K}^{+}$may also be transported by the sodium exchangers. In the model this function helped to control the level of $\mathrm{K}^{+}$ accumulation (Equation 21). Therefore, the parameters $K_{K, \text { exch }}^{\text {neur }}(800 \mathrm{mM})$ and $K_{K, \text { exch }}^{\text {glia }}(300$ $\mathrm{mM}$ ) were assumed as investigative parameters and adjusted along the simulation of the activities.

$$
\begin{array}{r}
\phi_{\mathrm{Na}}=Q_{\mathrm{Na} / \mathrm{H}} \frac{\left[\mathrm{Na}^{+}\right]_{i}}{[\mathrm{Na}]_{i}^{+}+K_{\mathrm{Na}-\operatorname{exch}}\left(1+\frac{\left[\mathrm{K}^{+}\right]_{i}}{K_{\mathrm{K}-\text { exch }}}\right)} \\
\phi_{\mathrm{K}}=Q_{\mathrm{Na} / \mathrm{H}} \frac{\left[\mathrm{K}^{+}\right]_{i}}{\left[\mathrm{~K}^{+}\right]_{i}+K_{\mathrm{K}-\operatorname{exch}}\left(1+\frac{\left[N a^{+}\right]_{i}}{K_{N a-\text { exch }}}\right)}
\end{array}
$$

The electric field effect on the extracellular space at the immediate vicinity of the sources was estimated by:

$$
\mathrm{V}_{\text {extra,fast }}=\tau \mathrm{TF} \sum_{\mathrm{n}=1}^{\mathrm{N}} \frac{\left(\Phi_{\mathrm{Na}, \text { fast }}^{\mathrm{NEURON}}+\Phi_{\mathrm{K}, \text { fast }}^{\mathrm{NEURON}}\right)_{\mathrm{n}}}{\mathrm{d}_{\mathrm{n}}},
$$

where $d_{n}$ means the distance between the current source ' $n$ ' and the neuron, and $\tau$ a constant that translates the resistivity of the medium at the vicinity of the neuron.

The $\tau$ changing in dependence on the intracellular volume change was described by:

$$
\tau=\bar{\tau}\left[\left(\frac{-1}{e^{-\frac{V o l_{\text {extra }}-2,97 \times 10^{-13}}{6 \times 10^{-16}}}+1}+1\right) \times 15+1\right]
$$

This equation was deduced to translate a sigmoidal dependence of $\tau$ on the $\mathrm{Vol}_{\text {extra, }}$ where

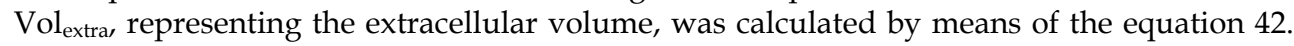
The parameter $\bar{\tau}\left(6.25 \times 10^{-3} \mathrm{mV} . \mathrm{s} / \mathrm{mM}\right)$ controls the population spikes amplitude and was adjusted to reproduce the typical amplitudes observed experimentally in our laboratory in the same conditions of the simulation. Therefore, this parameter was assumed as experimental parameter. 
The electric field effect on the membranes on the immediate vicinity of the sources was estimated by:

$$
\mathrm{I}_{\text {elect-effect }}=\varepsilon \mathrm{V}_{\text {extra,fast }},
$$

where $\varepsilon\left(7.30 \times 10^{-6} \mathrm{~mA} / \mathrm{mV} \cdot \mathrm{m}^{2}\right)$ was used to tune the field effect in the simulations. This experimental parameter was adjusted to reproduce the findings from Snow and Dudek (1986). It was tuned to obtain an electrical field effect to induce an intracellular depolarization around $50 \%$ of the population spikes.

Hence,

$$
\begin{gathered}
\frac{\partial[C]_{i}^{\text {NEURON }}}{\partial t}=-\Phi_{C(\text { INTRA } \rightarrow \text { EXTRA })}^{\text {NEURON }}-\Phi_{C, \text { Gap-Junction }}^{\text {NEURON }}, \\
\frac{\partial[C]_{i}^{\text {GLIA }}}{\partial t}=-\Phi_{C(\text { INTRA } \rightarrow \text { EXTRA })}^{\text {GLIA }}
\end{gathered}
$$

and

$$
\frac{\partial[C]_{o}}{\partial t}=\Phi_{C(\text { INTRA } \rightarrow \text { EXTRA })}^{\text {NEURON }}+\left(\frac{\partial[C]}{\partial t}\right)_{\text {Electrodiffusion }}+\Phi_{C(I N T R A \rightarrow E X T R A)}^{\text {GLIA }}
$$

where

$$
\begin{aligned}
& \Phi_{\mathrm{Na}(\mathrm{INTRA} \rightarrow E \mathrm{NXTRA})}^{\mathrm{NEURON}}=\Phi_{\mathrm{Na}, \text { fast }}^{\text {NEURON }}+\Phi_{\mathrm{Na}, \text { presist }}^{\text {NEURON }}+\Phi_{\mathrm{NKCC}}^{\text {NEURON }}+ \\
& 3 . \Phi_{P U M P}^{N E U R O N}+\Phi_{N a, \text { exchanger }}^{N E \text { IRON }}+\Phi_{N a, \text { leak }}^{\text {NEURON }} \\
& \Phi_{K(\text { INTRA } \rightarrow \text { EXTRA })}^{\text {NEURON }}=\Phi_{K, \text { fast }}^{\text {NEURON }}+\Phi_{K, \text { TypeA }}^{\text {NEURON }}+\Phi_{\text {NKCC }}^{\text {NEURON }}+\Phi_{K C C}^{\text {NEURON }}- \\
& -2 . \Phi_{\text {PUMP }}^{\text {NEURON }}+\Phi_{K, \text { exchanger }}^{\text {NEURON }}+\Phi_{K, \text { leak }}^{\text {NEURON }} \\
& \Phi_{\text {Cl(INTRA } \rightarrow \text { EXTRA })}^{\text {NEURON }}=\Phi_{C l}^{\text {NEURON }}+\Phi_{C l, \text { voltage }}^{\text {NEURON }}+2 \cdot \Phi_{\text {NKCC }}^{\text {NEURON }}+ \\
& \Phi_{\text {KCC }}^{\text {NEURON }}+\Phi_{C l \text {,exchanger }}^{\text {NEURON }}+\Phi_{C l \text {,leak }}^{\text {NEURON }}
\end{aligned}
$$

and

$$
\begin{aligned}
& \Phi_{N a(I N T R A \rightarrow E X T R A)}^{G L I A}=\Phi_{N a}^{G L I A}+\Phi_{N K C C}^{G L I A}+3 . \Phi_{P U M P}^{G L I A}+\Phi_{N a, \text { leak }}^{G L I A}+\Phi_{N a, \text { exchanger }}^{G L I A},
\end{aligned}
$$

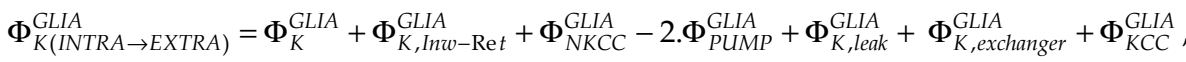

$$
\begin{aligned}
& \Phi_{C l(I N T R A \rightarrow E X T R A)}^{G L I A}=\Phi_{C l}^{G L I A}+2 \cdot \Phi_{N K C C}^{G L I A}+\Phi_{C l, l e a k}^{G L I A}+\Phi_{C l, \text { exchanger }}^{G L L A}+\Phi_{K C C}^{G L I A} .
\end{aligned}
$$

The equilibrium fluxes $\Phi_{N a, \text { leak }}^{\text {neuron }}\left(-1.73 \times 10^{-8} \mathrm{mmol} / \mathrm{s}^{2} \mathrm{~cm}^{2}\right), \Phi_{K, \text { leak }}^{\text {neuron }}\left(-3.95 \times 10^{-8} \mathrm{mmol} / \mathrm{s.cm}^{2}\right)$, $\Phi_{\text {Cl, leak }}^{\text {neuron }}\left(-3.00 \times 10^{-8} \mathrm{mmol} / \mathrm{s.cm}^{2}\right), \quad \Phi_{\mathrm{Na}, \text { leak }}^{\text {glia }}\left(-1.39 \times 10^{-7} \mathrm{mmol} / \mathrm{s.cm}^{2}\right)$, $\left.\Phi_{K, \text { leak }}^{\text {glia }}\left(-2.43 \times 10^{-7} \mathrm{mmol} / \mathrm{s.cm}\right)^{2}\right)$ and $\Phi_{C l, \text { leak }}^{\text {glia }}\left(-2.23 \times 10^{-7} \mathrm{mmol} / \mathrm{s.cm}{ }^{2}\right)$ are related to the 
steady state in normal conditions, therefore, before perfusion with high $\mathrm{K}^{+}$solution. In this sense, they were assumed as steady state parameters and adjusted to keep the resting conditions stable.

The equation used to calculate the extracellular electrodiffusion effect on the ionic concentration changes was:

$$
\left(\frac{\partial[\mathrm{C}]_{\mathrm{o}}}{\partial \mathrm{t}}\right)_{\text {Electrodiffusion }}=\frac{\mathrm{D}_{c}}{\lambda^{2}} \cdot \nabla^{2}[\mathrm{C}]_{\mathrm{o}}+\frac{\mathrm{z} \cdot \mathrm{F} \cdot \mathrm{D}_{\mathrm{c}}}{\mathrm{R} \cdot \mathrm{T} \cdot \lambda^{2}} \cdot \vec{\nabla}[\mathrm{C}]_{\mathrm{o}} \cdot \vec{\nabla} \mathrm{V}+\frac{\mathrm{z} \cdot \mathrm{F} \cdot \mathrm{D}_{\mathrm{c}}}{\mathrm{R} \cdot \mathrm{T} \cdot \lambda^{2}} \cdot[\mathrm{C}]_{\mathrm{o}} \cdot \nabla^{2} \mathrm{~V}
$$

The extracellular electrical field, $\vec{\nabla} \mathrm{V}$, was estimated by the following equation:

$$
\vec{\nabla} \mathrm{V}=-\frac{\mathrm{RT}}{\mathrm{F}} \frac{\mathrm{z}_{\mathrm{Na}} \mathrm{D}_{\mathrm{Na}} \vec{\nabla}\left[\mathrm{Na}^{+}\right]_{o}+\mathrm{z}_{\mathrm{K}} \mathrm{D}_{\mathrm{K}} \vec{\nabla}\left[\mathrm{K}^{+}\right]_{o}+\mathrm{z}_{\mathrm{Cl}} \mathrm{D}_{\mathrm{Cl}} \vec{\nabla}\left[\mathrm{Cl}^{-}\right]_{o}}{\mathrm{z}_{\mathrm{Na}}{ }^{2} \mathrm{D}_{\mathrm{Na}}\left[\mathrm{Na}^{+}\right]_{o}+\mathrm{z}_{\mathrm{K}}{ }^{2} \mathrm{D}_{\mathrm{K}}\left[\mathrm{K}^{+}\right]_{o}+\mathrm{z}_{\mathrm{Cl}}{ }^{2} \mathrm{D}_{\mathrm{Cl}}\left[\mathrm{Cl}^{-}\right]_{o}}+\vec{\nabla} V_{\text {extra, fast }},
$$

and $\nabla^{2} \mathrm{~V}$ was estimated in terms of the $\vec{\nabla} \mathrm{V}$. The first term of (35) was deduced assuming the continuity of the ionic currents along the extracellular space. The value of the parameters $D_{\mathrm{Na}}\left(1.33 \times 10^{-5} \mathrm{~cm}^{2} / \mathrm{s}\right), \mathrm{D}_{\mathrm{K}}\left(1.96 \times 10^{-5} \mathrm{~cm}^{2} / \mathrm{s}\right)$, and $\mathrm{D}_{\mathrm{Cl}}\left(2.03 \times 10^{-5} \mathrm{~cm}^{2} / \mathrm{s}\right)$, as constants, were obtained from the literature (Hille, 1992). The tortuosity $(\lambda=1.6)$ is an experimental parameter and along the granular layer was extracted from (Nicholson, 2001). In the case of the lateral shell of the network simulating this layer, the tortuosity was increased $(\lambda=4.0)$ aiming at representing the layers in between the solution and the granular layer. With this simplification, the computation could be reduced.

The functional unity dimensions, $\Delta x, \Delta y$ e $\Delta z$, were admitted equal to $20 \mu \mathrm{m}$, assuming that the diameters of the neuronal and glial cells can be considered around $10 \mu \mathrm{m}$. The iteration interval, $\Delta \mathrm{t}$, adopted was $0.1 \mathrm{~ms}$. This value was defined considering the compromise between the computational time of the simulations and the maximal numerical error acceptable.

The transmembrane potential was estimated by the following equation:

$$
\mathrm{V}_{\mathrm{m}}=\frac{\mathrm{RT}}{\mathrm{F}} \ln \left(\frac{\mathrm{P}_{\mathrm{Na}}\left[N a^{+}\right]_{o}+\mathrm{P}_{\mathrm{K}}\left[K^{+}\right]_{o}+\mathrm{P}_{\mathrm{Cl}}\left[\mathrm{Cl}^{-}\right]_{o}+\mathrm{P}_{\mathrm{A}}\left[A^{+}\right]_{o}+\mathrm{f}_{\mathrm{gj}}+\mathrm{f}_{\mathrm{ef}}+\gamma}{\mathrm{P}_{\mathrm{Na}}\left[N a^{+}\right]_{i}+\mathrm{P}_{\mathrm{K}}\left[K^{+}\right]_{i}+\mathrm{P}_{\mathrm{Cl}}\left[\mathrm{Cl}^{-}\right]_{i}+\mathrm{P}_{\mathrm{A}}\left[A^{+}\right]_{i}+2+\xi}\right),
$$

where

$$
f_{g j}=-\frac{I_{g j} A_{g j}}{A_{m}} \cdot\left(e^{\frac{F V_{m}}{R T}}-1\right) \cdot \frac{R T}{F^{2} V_{m}}+e^{\frac{F V_{m}}{R T}},
$$

with $\mathrm{I}_{\mathrm{g} j}$ representing the resultant current induced by all gap-junctions with the neighboring neurons, calculated by

$$
I_{g j}=\sum_{\substack{\text { NEURON= } \\ \text { NEIGHBORING }}} \sum_{C=N a, K, C l} z_{C} F \Phi_{C, \text { Gap-Junction }}^{\text {NEURON }}
$$

and

$$
f_{\text {ef }}=-I_{\text {elect-effect }} \cdot\left(e^{\frac{F V_{m}}{R T}}-1\right) \cdot \frac{R T}{F^{2} V_{m}}+e^{\frac{F V_{m}}{R T}}
$$


where $\mathrm{I}_{\text {elect-effect }}$ is the current referred to the electric field effect, and $\gamma$ and $\zeta$ representing the ionic leakage through the membrane. The parameters $\gamma^{\text {neur }}(8 \mathrm{mMcm} / \mathrm{s}), \xi^{\text {neur }}(72 \mathrm{mMcm} / \mathrm{s})$, yglia $(1 \mathrm{mMcm} / \mathrm{s})$ and $\xi$ glia $(70 \mathrm{mMcm} / \mathrm{s})$ were adjusted aiming at establishing transmembrane potentials, for neurons and glial cells, in the same range observed experimentally (Pan \& Stringer, 1996) and, therefore, were assumed as steady state parameters. The superficial area of the neuronal membrane, $\mathrm{A}_{\mathrm{m}}$, was estimated assuming a spherical cellular body for the granular cells and with diameter equal to $20 \mu \mathrm{m}$. This allowed to estimate $A_{m}=1.26 \times 10^{-5} \mathrm{~cm}^{2}$. The parameter $A_{g j}$, which represents the area of each gapjunction pore, is equal to $1.77 \times 10^{-14} \mathrm{~cm}^{2}$ (Jeffery, 1995).

The extracellular field potential sensed by a microelectrode was calculated in terms of the extracellular electric field, as the following equation describes:

$$
V_{e x t}=-\int_{\lambda} \vec{\nabla} V \cdot d \vec{l},
$$

where $\lambda$ represented a trajectory linking the electrode tip position to a remote point in the bath solution.

The following equation describes the volume change of the cells and the extracellular space:

$$
\frac{d V o l_{\text {int-neur }}}{d t}=v\left(\sum_{C=N a, K, C l}[C]_{o}+[S]_{i}-\sum_{C=N a, K, C l}[C]_{i}+[S]_{o}\right),
$$

where

$$
V o l_{\text {extra }}=V o l_{\text {total, constan } t}-V_{\text {ol }} l_{\text {int-neur }},
$$

$[S]^{i}=n_{s}^{i} / V_{0} l^{\text {intra,neur }},[S]^{o}=n_{s}^{o} / V^{\text {int } r a, \text { neur }}, n_{s}^{i}(9.01 \times 10-10 \mathrm{mmol})$ and $n_{s}^{o}\left(3.15 \times 10^{-11}\right.$ $\mathrm{mmol})$ represent the quantity of the impermeant solutes $S, V o l^{\text {int ra-neur }}\left(4.19 \times 10^{-12} \mathrm{dm}^{3}\right)$ the neuronal intracellular volume, $\operatorname{Vol}_{\text {extra }}\left(3.15 \times 10^{-13} \mathrm{dm}^{3}\right)$ the extracellular volume of the functional unit and $\operatorname{Vol}_{\text {total,constant }}\left(4.19 \times 10^{-12} \mathrm{dm}^{3}\right)$ the total volume of the functional unit. The parameters $v\left(4.50 \times 10^{-17} \mathrm{~cm}^{2} / \mathrm{s}\right)$ and $n_{s}^{o}(3.15 \times 10-11 \mathrm{mmol})$, assumed as investigative parameters, act on the cell volume variation along of the neuronal discharges. The parameter $n_{s}^{i}(9.01 \times 10-10 \mathrm{mmol})$ is a steady state parameter and was adjusted to keep the volume constant when the system is in steady state conditions.

The neuronal and glial initial volumes were determined considering spherical cellular bodies with diameter equal to $20 \mu \mathrm{m}$. The extracellular volume was calculated according to the extracellular volume fraction, assumed equal to 0.07 , considering that the bursts inductions were obtained placing the slices in an interface chamber.

Some parameters were involved in almost all equations described above. This is the case of the initial ionic concentrations of the extracellular medium $\left([\mathrm{Na}]_{\mathrm{o}}=131 \mathrm{mM},[\mathrm{K}]_{\mathrm{o}}=4 \mathrm{mM}\right.$, $\left.[\mathrm{Cl}]_{\mathrm{o}}=130 \mathrm{mM}\right)$. These values were admitted equal to the values commonly used in the experimental investigations. The intracellular concentrations $\left([\mathrm{Na}]_{\mathrm{i} \text {,neur }}=10 \mathrm{mM},[\mathrm{K}]_{\mathrm{i} \text {,neur }}=\right.$ $\left.130 \mathrm{mM},[\mathrm{Cl}]_{\mathrm{i}, \text { neur }}=9 \mathrm{mM},[\mathrm{Na}]_{\mathrm{i}, \text { glia }}=10 \mathrm{mM},[\mathrm{K}]_{\mathrm{i}, \text { glia }}=130 \mathrm{mM},[\mathrm{Cl}]_{\mathrm{i}, \text { glia }}=9 \mathrm{mM}\right)$ were adjusted in the ranges normally assumed experimentally (Kager et al., 2002; Xiong \& Stringer, 2000; Almeida et al, 2004). The neuronal transmembrane potential at the steady state was considered equal to $-69 \mathrm{mV}$. This value was assumed reasonable because 
experimentally the $\mathrm{Ca}^{2+}$-free solution induces a desinhibition that leads to a depolarization around the same level (Pan \& Stringer, 1996). For glial cells, the initial transmembrane potential was set around $-79 \mathrm{mV}$ and this value is in the range of the experimental observations (Orkand, 1991). Normally, it is assumed that the glial intracellular potential is more negative because of the elevated $\mathrm{K}^{+}$permeability of the membrane of these cells.

The equations of the model were solved numerically by means of the finite difference method and the maximum error tolerance was $10^{-4}$. The computational language used was FORTRAN 90. To run the simulations, a computer cluster was necessary. The main configuration used for the simulations presented: (1) One front end Athlon 64 3000+ Dual Core, 2 GB RAM, 300 GB HD; (2) 10 Slaves Athlon 64 3000+ Dual Core, 2 GB RAM, 80 GB HD; (3) One switch with 16 ports; (4) Operational System Rocks Cluster 4.1 (Linux), and (5) FORTRAN 90 and MPI (message passing interface).

\subsection{Investigating the biophysics of the nonsynaptic epileptiform activity}

Comparing the measured and simulated extracellular potential, as shown in Fig. 8, it can be observed that all main features of the extracellular potential were captured by the simulations. The simulation corresponds to the experimental maneuver for inducing the nonsynaptic epileptiform activities. The $\left[\mathrm{K}^{+}\right]_{\mathrm{o}}$ of the compartments representing the bath solution was increased from 4 to $8 \mathrm{mM}$. The cells of the network were coupled exclusively with nonsynaptic connections, as described in item 5.1, aiming at representing the deletion of $\mathrm{Ca}^{2+}$ in the bath solution. The great advantage offered by the computational simulation is that once the experimental data are reproduced, then it is possible to analyze all mechanisms and variables involved and infer about the biophysics.

The model allows predicting the concomitant concentration changes along the period preceding the paroxysm induction and also along the paroxysm, when the interictal and ictal states transitions occur, as it is seen in Fig. 8. The DC-shift components of the nonsynaptic events simulated were in agreement with the experimental data and were calculated (see equations 35 and 36) based on the hypothesis of being generated by a Goldman-Hodgkin-Katz potential established along the extracellular space, therefore, the same mechanism proposed for the DC-shift during spreading depression (Almeida et al., 2004).

As described in our previous work (Almeida et al. 2008), the simulations show that $\mathrm{Cl}^{-}$ concentration changes, in response to the $\left[\mathrm{K}^{+}\right]_{\mathrm{o}}$ increase, are able to promote the $\mathrm{Cl}^{-}$Nernst potential overcoming the transmembrane potential (Fig. 8). These changes are the main responsible cause of the excitation sustained along of the paroxysm. Therefore, it should be treated as a target for the paroxysms reduction. This means that the mechanisms involved must be investigated. The first step is to analyze the ion flux of each mechanism, shown in Fig. 8. It can be observed that the cotransporters, in particular the NKCC, exhibited valuable contributions for the changes, differently from the exchangers, which were almost insensitive to the $\left[\mathrm{K}^{+}\right]_{\mathrm{o}}$ increase. Before induction, the $\mathrm{Cl}$ - efflux by $\mathrm{KCC}$ was greater than its influx by NKCC and this situation changed in the course of the induction. This can also be associated with situations in which the excitability of a brain region increases and the recruited neuronal depolarization is enough to increase the $\left[\mathrm{K}^{+}\right]_{\mathrm{o}}$. From the simulation we can propose that brain regions under these circumstances are able to induce nonsynaptic epileptiform activity. The biophysical process captured by the simulation can then be described. In normal conditions, the KCC cotransporter is responsible for the $\mathrm{Cl}$ - extrusion, counteracted by the NKCC cotransporter, which is in charge of the $\mathrm{Cl}^{-}$influx. The $\left[\mathrm{K}^{+}\right]_{\mathrm{o}}$ 
elevation increases the driving force for NKCC influx. This influx increase provides more $\mathrm{Cl}^{-}$ to the intracellular space, increasing, by its turn, the driving force for KCC extrusion. However, the dynamic equilibrium occurs for $\mathrm{Cl}^{-}$accumulated in the intracellular space. This accumulation is sufficient to make the $\mathrm{Cl}^{-}$Nernst potential overcoming the transmembrane potential. In these circumstances, the inward $\mathrm{Cl}^{-}$current through the channels become outward, inducing the neuronal depolarization.

The simulations showing the concomitant ionic concentration changes and fluxes allow analyzing the mechanisms acting along the transitions between itcal and interictal states. AS shown in Fig. 8 , in the extracellular space, the $\left[\mathrm{Na}^{+}\right]$and $\left[\mathrm{Cl}^{-}\right]$decreased quickly at the transition of the states, reached a trough, followed by a slow increase until the end of the ictal state (transition to the interictal state), from which the concentrations returned quickly to the baseline. Almost the same behavior was exhibited by the $\left[\mathrm{K}^{+}\right]_{\mathrm{o}}$, however in an inverted manner. In the neuronal intracellular space, the simulations showed, during the ictal state, the $\left[\mathrm{Na}^{+}\right]$and $\left[\mathrm{Cl}^{-}\right]$increasing slowly and monotonically and $\left[\mathrm{K}^{+}\right]$decreasing also monotonically. The recovery of the concentrations along the interictal state did not have the same time course. Different from the extracellular, where the concentrations return quickly to the baseline, in the intracellular the $\left[\mathrm{K}^{+}\right]$increase covers almost the entire interictal state, as well as the $\left[\mathrm{Na}^{+}\right]$and $\left[\mathrm{Cl}^{-}\right]$reduction. Of course, these changes have a definitive influence on the Nernst potential of each ionic specie and, therefore, on the excitability.

During the ictal period, the direction of the transmembrane passive ionic fluxes simulated, as illustrated in Fig. 8, in almost all the cases, were guided by the transmembrane concentration gradient. The $\mathrm{Na}^{+}$flux through the ionic channels was directed to the intracellular space and the $\mathrm{K}^{+}$to the extracellular. The $\mathrm{Cl}^{-}$flux direction was in some situations against its transmembrane concentration gradient, sustained by the transmembrane electric field originated from the Nernst potential of this ion overcoming the transmembrane potential. According to the simulations, these were observed during the interictal state and during the interval between subsequent action potentials along the ictal period (Almeida et.al, 2008).

Through the $\mathrm{Na} / \mathrm{K}$ pump, the $\mathrm{Na}^{+}$and $\mathrm{K}^{+}$fluxes were, as expected, against their gradients. Sensitive to intracellular $\mathrm{Na}^{+}$, the pump increased its activity during the ictal period, when $\mathrm{Na}^{+}$accumulated in the intracellular space. Only about the end of the period, the pump started to decrease the $\mathrm{Na}^{+}$efflux. This decrease happened simultaneously with the $\mathrm{Na}^{+}$ influx decrease through the voltage dependent channels. The $\mathrm{Na}^{+}$influx by the cotransporter NKCC as well as its efflux by the $\mathrm{Na}^{+} / \mathrm{H}^{+}$exchanger had minor changes on their intensities along the neuronal activity transition from the interictal to the ictal state. However, their baselines showed significant magnitude, sustaining the ionic equilibrium during the interictal state (Fig. 8). The $\mathrm{K}^{+}$influx through the pump, in comparison with its efflux through the channels, behaves similarly to $\mathrm{Na}^{+}$, however, with inverted flow direction. The $\mathrm{K}^{+}$fluxes through the NKCC cotransporter and the $\mathrm{Na}^{+} / \mathrm{H}^{+}$exchanger also had the same behavior as described for $\mathrm{Na}^{+}$and its $\mathrm{H}^{+}$exchanger. On the other hand, the neuronal KCC cotransporter not only had a significant baseline, but the changes on the transitions from the interictal to ictal states were also prominent. The $\mathrm{Cl}^{-}$fluxes simulated suggest that the cotransporter mechanisms were the ones mainly responsible for the intraand extracellular concentration changes of this ion. The $\mathrm{Cl}^{-}$accumulation in the intracellular space during the ictal state was mediated by the NKCC cotransporter, which happened with almost the same flux along of the ictal state. The $\mathrm{Cl}^{-}$efflux was dominated by the $\mathrm{KCC}$ cotransporter and during the ictal state it was always smaller than the $\mathrm{Cl}^{-} \mathrm{NKCC}$ influx. 
Only at the transition between the ictal/interictal states, the KCC efflux overcame the NKCC influx and was responsible for the intracellular $\mathrm{Cl}^{-}$concentration decrease.

(A)

(B)

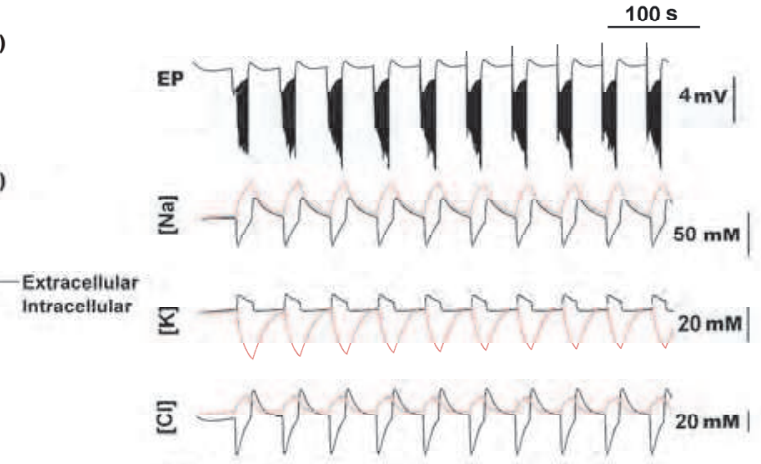

(C)

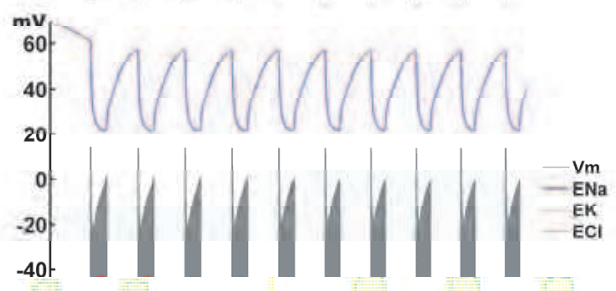

(D)

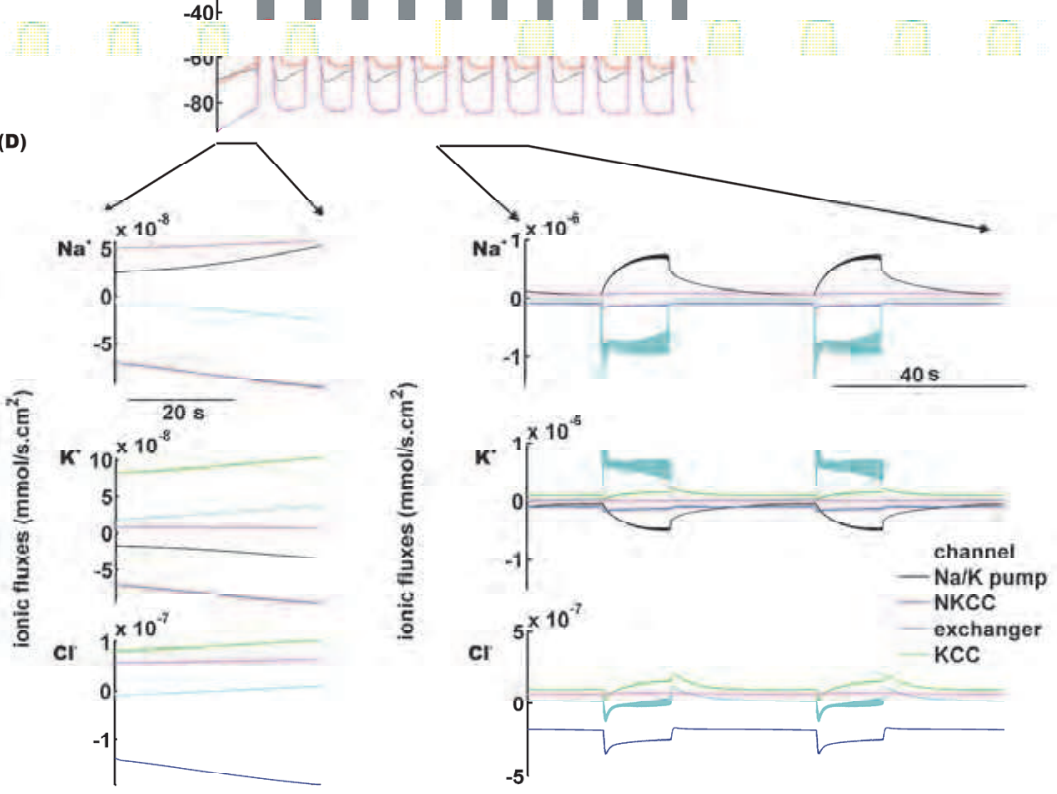

Fig. 8. Nonsynaptic epileptiforme activity simulated. (A) Extracellular potential;

Concomitantly, (B) intra- and extra-cellular ionic concentrations and (C) Nernst potential for $\mathrm{Na}^{+}, \mathrm{K}^{+}$and $\mathrm{Cl}^{-}$, and the transmembrane potential. Detailed in (D) the fluxes associated with each nonsynaptic mechanism considered in the model. 
Observations on the effect of the antiepileptic furosemide (Geck\& Pfeiffer, 1985; AlvarezLeefman, 1990) are in accordance with the hypothetical $\mathrm{Cl}^{-}$current sustaining the nonsynaptic epileptiform activities. It has been observed that furosemide, a blocker of the NKCC and KCC cotransporters, blocks spontaneous epileptiform activities induced in a variety of experimental maneuvers and models. The blockage can be explained considering the blockage of the net effect of both cotransporters, therefore the $\mathrm{Cl}$ - influx. This suggests that the preferential blockage or depression of the NKCC activities would be more efficient and that it would be a possible target for an antiepileptic drug. The simulation of this hypothesis, shown in Fig. 9, confirms the assumption and experimental observations also corroborate this finding (Haglund \& Hochman, 2005).

(A)
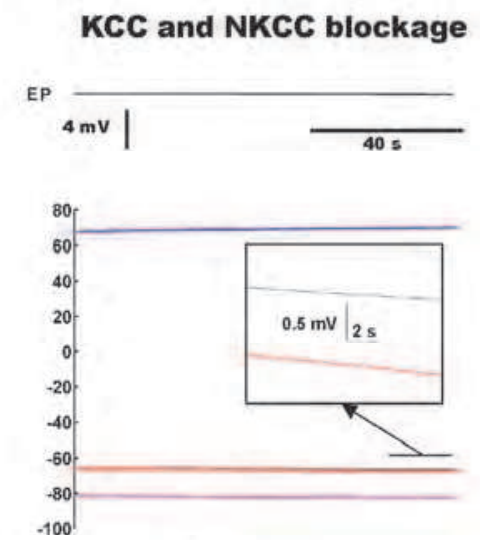

(C)

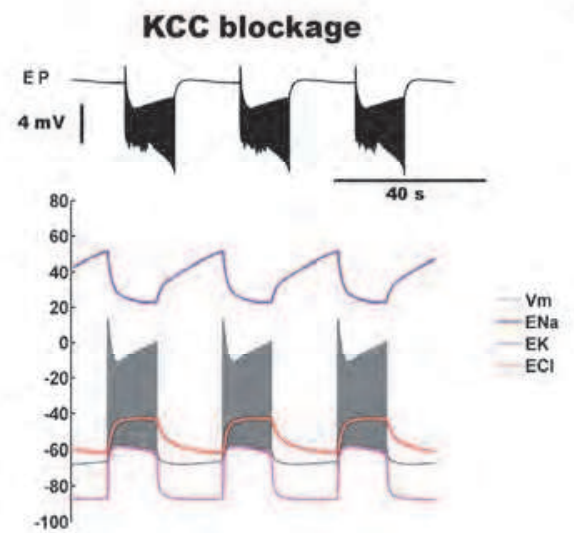

(B)
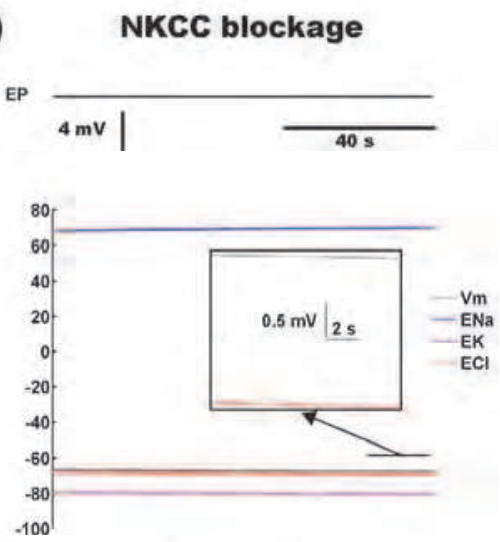

(D) Bromide

EP
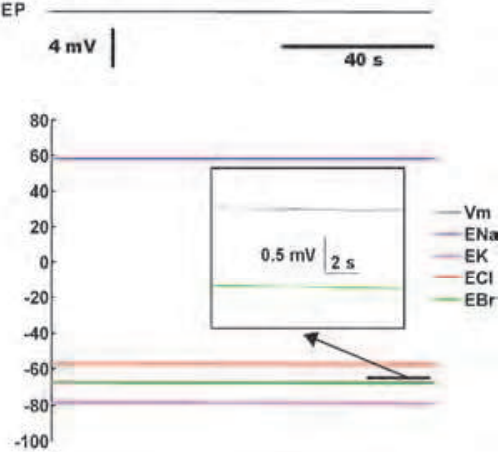

Fig. 9. Simulated experimental maneuver. (A) simultaneous blockage of NKCC and KCC, inducing a $\mathrm{Cl}$ - Nernst potential negative in respect to the transmembrane potential. (B) NKCC blockage, when the polarization is even more effective than in (B). (C) KCC blockage, promoting excitability increase. (D) Inhibition by means of the negativity of the Br- Nernst potential in respect to the membrane potential. 
Focusing the same target, another possible strategy for the seizure control would be to counteract the $\mathrm{Cl}^{-}$Nernst potential depolarization. An anion capable of permeating the $\mathrm{Cl}^{-}$ channels and, at the same time, having low affinity to KCC and NKCC enzymes - thus able to sustain a more negative Nernst potential - would be a good candidate. In fact, this seems to be the bromide effect, whose mechanisms are being investigated in our group. A simulation of the resultant effect of such kind of anion is shown in Fig. 9.

Analyzing the excitatory and inhibitory contributions of each mechanism involved (Almeida et al. 2008) it was possible to demonstrate that the $\mathrm{Na}^{+}$current was the most intense during the ictal state and that it was counteracted along the whole ictal state by the $\mathrm{Na} / \mathrm{K}$ pump electrogenic current. The simulations shown in Fig. 10 suggest that it was exactly when the electrogenic current pump overcame the $\mathrm{Na}^{+}$current through the channels that the ictal states finalized, therefore, the ictal/interictal transition took place. In contrast, along the interictal state, the $\mathrm{Cl}^{-}$current was the most prominent. This current decreased

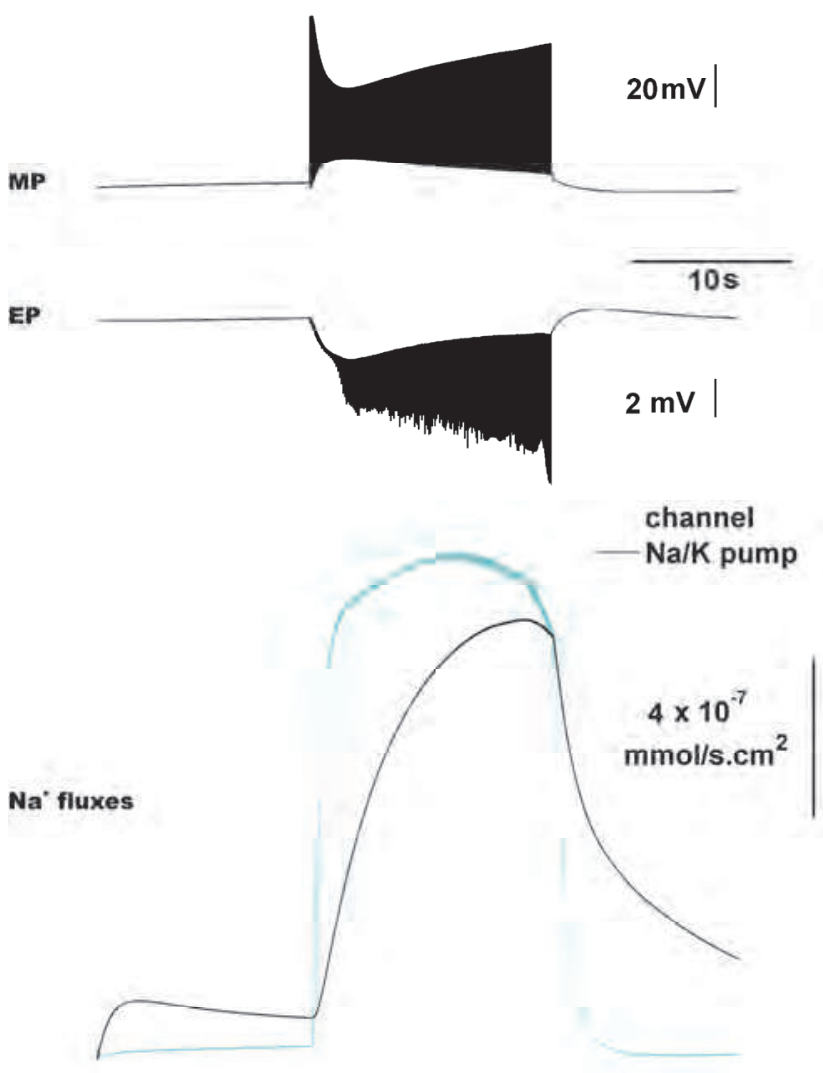

Fig. 10. Nonsynaptic burst simulation. (MP) membrane potential; (EP) extracellular potential. $\mathrm{Na}^{+}$fluxes shown on the bottom traces: (blue) voltage dependent channels. (black) $\mathrm{Na} / \mathrm{K}$ pump. When the efflux trough the $\mathrm{Na} / \mathrm{K}$ pump overcame the influx trough the voltage dependent channels, the event terminates. 
during the state and, at the same time, $\mathrm{Na}^{+}$current increased in almost the same rate. The crossing point of the currents occurred about the end of the state and was immediately followed by the transition point between the interictal/ictal states. The most important contributors for this transition were again $\mathrm{Na}^{+}$current and the pump electrogenic current. The abrupt increase of the $\mathrm{Na}^{+}$current allowed the excitatory current overcoming the inhibitory pump current due to the electrogenic effect. These observations emphasize the importance to target the $\mathrm{Cl}^{-}$mechanisms responsible for its intracellular accumulation and also to counteract is Nernst potential. Additionally, the $\mathrm{Na}^{+}$influx is also revealed as another possible target, placing in perspective strategies to antagonize ionic currents through $\mathrm{Na}^{+}$persistent channels.

\section{Possible targets for controlling refractory seizures}

From the biophysical mechanisms suggested by the simulations, the therapeutic use of bumetanide and bromide may be proposed combined for the treatment of patients with refractory epilepsy (Almeida et al., 2011). Bumetanide would reduce intracellular chloride concentration and bromide would reinforce $\mathrm{E}_{\mathrm{GABA}}$ negativity, as seen in Fig. 9, where the systemic effects of bumetanide and bromide are depicted. Although acting through different mechanisms, both drugs reduce neuronal excitability. Once the effects are complementary, the doses of bumetanide and bromide could be reduced and, consequently, their side effects

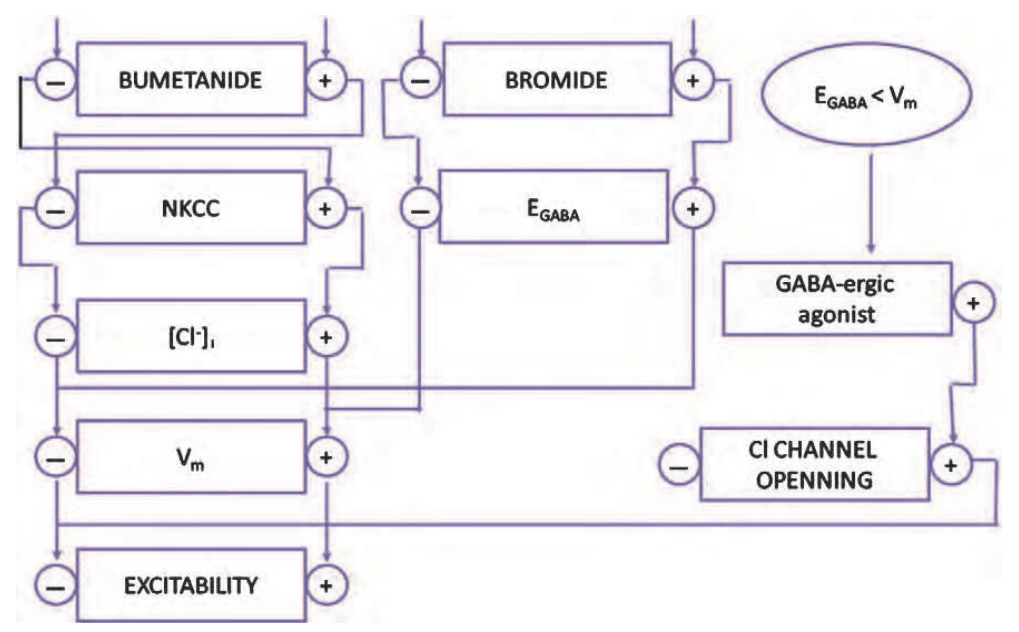

Fig. 11. Block diagram indicating the systemic action of the conjoint effect of bumetanide, bromide, and $\mathrm{GABA}_{\mathrm{A}}$ agonist. Bromide acts by blocking NKCC activity. This co-transporter is responsible for $\mathrm{Cl}$ - influx, which induces the accumulation of this ion in the intracellular space, inducing an increase in excitability. An NKCC antagonist is, therefore, able to counteract the chloride accumulation, decreasing excitability. Bromide acts directly on $\mathrm{E}_{\mathrm{GABA}}$, improving its negativity and also decreasing excitability. The conjoint effects of an NKCC antagonist and bromide are therefore complementary. The clinical observation of seizure reduction could be indicative of induced $\mathrm{E}_{\mathrm{GABA}}$ negativity with respect to $\mathrm{Vm}$ (intracellular potential), when the use of GABAergic drugs can be useful. $\mathrm{NKCC}=\mathrm{Na}^{+}, \mathrm{K}^{+}$, 2Cl- co-transporter; $\mathrm{E}_{\mathrm{GABA}}=\mathrm{GABA}$ reverse potential. Extracted from Almeida et al. 2011. 
would be minimized as well. In fact, in a recent case reported on the use of bumetanide for treatment of autism, the authors did not observe, at the dosage investigated, any side effect (Franciolini \& Nonner, 1987). To overcome the severe side effects of bromide described (Meierkord et al., 2000), it is paramount that bromide be administered with care, that followup testing be carried out, and that serum bromide levels be monitored periodically. We also propose that effort should be directed to find anions or anionic compounds that can replace bromide with the aim of avoiding its side effects. These proposals reflect a new perspective on the use of bromide: valuing its clinical efficacy associated with a reduction of its side effects. Furthermore, we also hypothesize that clinical observation of seizure reduction would be indicative of $\mathrm{E}_{\mathrm{GABA}}$ negativity (Fig. 11). Under such clinical conditions, after the effect of bumetanide and bromide has already been established, shifting GABA from excitation to inhibition, the administration of GABA agonists should be considered in the treatment of uncontrollable seizures. With the action of these agonists, it is assumed that the doses of bumetanide and bromide could be further reduced.

\section{Conclusion}

The investigation of the biophysical aspects of the nonsynaptic epileptiform activities may guide the design of experimental investigations aiming at unraveling the intricate interdependence of the several process that are not only responsible for the neuronal activities but also for the ionic homeostasis of the whole network. The development of antiepileptic medications targeted to the conditions that sustain seizures would be facilitated if the basic mechanisms, in terms of their complex interdependence during normal or epileptiform activities, were taken into consideration. Such kind of approach would offer the necessary information for designing pharmacological agents able to antagonize the interplay of the mechanisms responsible for maintaining the homeostasis that favour the conditions for the abnormal functions.

\section{Acknowledgment}

This work was supported by Fundação de Amparo à Pesquisa do Estado de Minas Gerais (FAPEMIG), Conselho Nacional de Desenvolvimento Científico e Tecnológico (CNPq), PROCAD/Coordenação de Aperfeiçoamento de Pessoal de Nível Superior (CAPES), Pandurata Ltda, FAPESP, CInAPCe-FAPESP and FAPESP/CNPq/MCT- Instituto Nacional de Neurociência Translacional.

\section{References}

Almeida, A.; Texeira, H.; Duarte, M. \& Infantosi, A. (2004). Modeling extracellular space electrodiffusion during Leão's spreading depression, IEEE Trans Biomed Eng, Vol. 51, No. 3, (March), pp. 450-458, ISSN 0018-9294

Almeida, A.; Rodrigues, A.; Scorza, F.; Cavalheiro. E.; Teixeira HZ, Duarte MA, Silveira G. \& Arruda, E. (2008). Mechanistic hypotheses for nonsynaptic epileptiform activity induction and its transition from the interictal to ictal state--computational simulation, Epilepsia, Vol. 49, No. 11, (November), pp. 1908-1924, ISSN 1528-1167

Almeida, A.; Scorza, F.; Rodrigues, A.; Arida, R.; Carlesso, F.; Batista, A.; Duarte, M. \& DaCosta, J. (2011). Combined effect of bumetanide, bromide, and GABAergic 
agonists: an alternative treatment for intractable seizures, Epilepsy Behav, Vol. 20, No. 1, (January), pp. 147-149, ISSN 1525-5050

Alverez-Leefman F. (1990). Intracellular Cl- regulation and synaptic inhibition in vertebrate and invertebrate neurons. In: Chloride channels and carriers in nerve, muscle, and glial cells, Alvarez-Leefmans FJ, Russell JM, pp. 109-158. Plenum, ISBN-10: 0306434261 New York

Andrew, R.; Adams, J. \& Polischuk, T. (1996). Imaging NMDA- and kainate-induced intrinsic optical signals from the hippocampal slice, J Neurophysiol. Vol. 76, No. 4, (October), pp. 2707-2717, ISSN 0022-3077

Barmashenko, G.; Kockskamper, J. \& Glitsch, H. (1999). Depolarization increases the apparent affinity of the Na+-K+ pump to cytoplasmic Na+ in isolated guinea-pig ventricular myocytes, J Physiol Vol. 517, No. 15, (Jun), pp. 691-698, 0022-3751

Bikson, M.; Ghai, R.; Baraban, S. \& Durand DM. (1999). Modulation of burst frequency, durantion, and amplitude in the zero- $\mathrm{Ca}(2+)$ model of epileptiform activity, $J$ Neurophysiol, Vol. 82, No.: 5, (November), pp. 2262-2270, ISSN 0022-3077

Bikson, M.; Baraban, S. \& Durand, D. (2002) Conditions sufficient for nonsynaptic epileptogenesis in the CA1 region of hippocampal slices, J Neurophysiol, Vol. 87, No. 1, (January), pp. 62-71, ISSN 0022-3077

Blaesse, P.; Airaksinen, M.; Rivera, C. \& Kaila, K. (2009). Cation-Chloride Cotransporters and Neuronal Function, Neuron, Vol.61, No. 6, pp. 820-838, ISSN 0896-6273

Chesler, M. (2003). Regulation and modulation of pH in the brain, Physiol Rev, Vol. 83, No. 4, (October), pp.1183-1221, ISSN 0031-9333

Dudek, F.; Snow, R. \& Taylor, C. (1986). Role of electrical interactions in synchronization of epileptiform bursts, Adv Neurol, Vol. 44, pp. 593-617, ISSN 0091-3952

Dudek, F.; Obenaus, A. \& Tasker, J. (1990). Osmolality-induced changes in extracellular volume alter epileptiform bursts independent of chemical synapses in the rat: importance of non-synaptic mechanisms in hippocampal epileptogenesis. Neurosci Lett, Vol. 11, No. 2, (December), pp. 267-270, ISSN 0304-3940

Franciolini, F. \& Nonner, W. (1987). Anion and cation permeability of a chloride channel in rat hippocampal neurons. J Gen Physiol, Vol. 90, No. 4, (October), pp. 453-478, ISSN 0022-1295

Friedrich, T.; Bamberg, E. \& Nagel, G. (1996). Na+,K+-ATPase pump currents in giant excised patches activated by an ATP concentration jump. Biophys. J., Vol. 71, No. 5, (Nov), pp. 2486-2500, ISSN 0006-3495

Geck, P. \& Pfeiffer, B. (1985). Na++ K++ 2Cl-cotransport in animal cells -its role in volume regulation. Ann N Y Acad Sci, Vol. 456, pp. 166-182, ISSN 0077-8923

Glitsch, H. (2001). Electrophysiology of the sodium-potassium-ATPase in cardiac cells. Physiol. Rev, Vol. 81, No. 4, (October), pp 1791-1826, ISSN 0031-9333

Hansen, P.; Buhagiar, K.; Kong, B. (2002). Dependence of $\mathrm{Na}^{+}-\mathrm{K}^{+}$pump current-voltage relationship on intracellular $\mathrm{Na}^{+}, \mathrm{K}^{+}$and $\mathrm{Cs}^{+}$in rabbit cardiac myocytes. Am J Physiol Cell Physiol, Vol. 283, (Dec), pp. C1511-1521, ISSN 0363-6143

Heinemann, U.; Lux, H. \& Gutnick, M. (1977). Extracellular free calcium and potassium during paroxysmal activity in cerebral cortex of the cat. Exp Brain Res, Vol. 27, No. 3-4, (March), pp. 237-243, ISSN 0014-4819

Heyse. S.; Wuddel, I.; Apell, H. \& Sturmer, W. (1994). Partial reactions of the Na, K-ATPase: determination of rate constants. J Gen Physiol, Vol. 104, No. 2, (August), pp.197-240, ISSN 0022-1295 
Hille, B. (1992). Ionic channels of excitable membranes (2nd ed.), Sinauer Associates, Inc., ISBN 0878933239, Sunderland, MA.

Hochman, D.; D'Ambrosio, R.; Janigro, D. \& Schwartzkroin, P. (1999). Extracellular chloride and the maintenance of spontaneous epileptiform activity in rat hippocampal slices. J Neurophysiol, Vol. 81, No. 1, (January), pp. 49-59, ISSN 0022-3077

Haglund, M. \& Hochman, D. (2005). Furosemide and mannitol suppression of epileptic activity in the human brain. J Neurophysiol, Vol. 94, No. 2, (August),, pp. 907-918, ISSN 0022-3077

Horisberger, J. (2004). Recent insights into the structure and mechanism of the sodium pump. Physiology, Vol. 19, (December), pp. 377-387, ISSN: 1548-9213

Jefferys, J. (1995). Nonsynaptic modulation of neuronal activity in the brain: electric currents and extracellular ions. Physiol Rev, Vol. 75, No. 4, (October), pp. 689-723, ISSN 00319333

Jefferys, J. \& Haas, H. (1982). Synchronized burstings of CA1 pyramidal cells in the absence of synaptic transmission. Nature, Vol. 300, No. 5891, (December), pp. 448-450, ISSN 0028-0836

Kager, H.; Wadman, W. \& Somjen G. (2007). Seizure-like afterdischargers simulated in a model neuron. J Comput Neurosci, Vol. 22, No. 2, (April), pp. 105-128, ISSN 0929-5313

Konnerth, A.; Heinemann, U. \& Yaari, Y. (1986). Nonsynaptic epileptogenesis in the mammalian hippocampus in vitro. I. Development of seizurelike activity in low extracellular calcium. J Neurophysiol, Vol. 56, No. 2, (August), pp. 409-423, ISSN 0022-3077

Krnjevic, K.; Morris, M. \& Reiffenstein, R. (1980). Changes in extracellular $\mathrm{Ca}^{2+}$ and $\mathrm{K}^{+}$ activity accompanying hippocampal discharges. Can J Physiol Pharmacol, Vol. 58, No. 5, (May), pp. 570-583, ISSN 0008-4212

MacVicar, B. \& Dudek, F. (1982). Electrotonic coupling between granule cells of rat dentate gyrus: physiological and anatomical evidence. J Neurophysiol, Vol. 47, No. 4, (April), pp. 579-592, ISSN 0022-3077

Meierkord, H.; Grünig, F. ; Gutschmidt U, et al. (2000). Sodium bromide: effects on different patterns of epileptiform activity, extracellular $\mathrm{pH}$ changes and GABAergic inhibition. Naunyn Schmiedebergs Arch Pharmacol, Vol. 361, No. 1, (January), pp. 2532, ISSN: 0028-1298

Nakao, M. \& Gadsby, D. (1989). [Na] and [K] Dependence of the Na/K Pump CurrentVoltage Relationship in Guinea Pig Ventricular Myocytes. J. Gen. Physiol. Vol. 94, No. 3, (September), pp. 539-565, ISSN 0022-1295

Naus, C.; Bechberger, J.; Caveney, S; \& Wilson, J. (1991). Expression of gap junction genes in astrocytes and C6 glioma cells. Neurosci Lett. Vol. 126, No. 1, (May), pp. 33-36

Nicholson, C. (2001). Diffusion and related transport mechanisms in brain tissue. Rep. Prog. Phys, Vol. 64, No. 7, (July), 815-884, ISSN 0034-4885

Orkand, R. (1991). Glial Electrophysiology and Transport. Annals of the New York Academy of Sciences. Vol. 633, (December), pp. 245-247, ISSN 0077-8923

Pan, E. \& Stringer, J. (1996). Burst Characteristics of dentate gyrus granule cells: evidence for endogenous and nonsynaptic properties. J Neurophysiol, Vol. 75, No. 1, (January), pp. 124-132, ISSN 0022-3077

Payne, J. (1997). Functional characterization of the neuronal-specific K-Cl cotransporter: implications for $\left[\mathrm{K}^{+}\right]_{\mathrm{o}}$. Am J Physiol, Vol. 273, Vol. 5, (November), pp. C1516-C1525, ISSN 0363-6143 
Perez-Velazques JL, Valiant TA, Carlen PL. (1994). Modulation of gap junction mechanisms during calcium-free induced field activity: a possible role for electrotonic coupling in epileptogenesis. J Neurophysiol, Vol.14, No. 7, (July), pp. 4308-4317, ISSN 0022-3077

Rodrigues, A.; Almeida, A. \& Infantosi, A. (2008). Effect of palytoxin on the sodiumpotassium pump: model and simulation. Phys Biol, Vol. 5, No. 3, (July), pp. 036005 1-11, ISSN 1478-3967

Roper, S.; Obenaus, A. and Dudek, F. (1992). Osmolality and nonsynptic epileptiform bursts in rat CA1 and dentate gyrus. Ann Neurol, Vol. 31, No. 1, (January), pp. 81-85, ISSN 0364-5134

Russell, J. (2000). Sodium-potassium-chloride cotransport. Physiol Rev, Vol. 80, No.1, (January), pp. 211-276, ISSN 0031-9333

Scheiner-Bobis, G. (2002). The sodium pump. Its molecular properties and mechanics of ion transport. Eur. J. Biochem, Vol. 269, No. 10, (May), pp. 2424-2433, ISSN 0014-2956

Schwartzkroin, P. (1975). Characteristics of CA1 Neurons Recorded Intracellularly in the Hippocampal in Vitro Slice Preparation, Brain Res, v. 85, No. 3, (March), p. 423-436, ISSN 0006-8993

Schwartzkroin, P.; Baraban, S. \& Hochman, D. (1998). Osmolarity, ionic flux, and changes in brain excitability. Epilepsy Res, Vol. 32, No. 1-2, (September), pp. 275-285, ISSN 0920-1211

Schweitzer, J.; Patrylo, P. \& Dudek, F. (1992). Prolonged field bursts in the dentate gyrus: dependence on low calcium, high potassium, and nonsynaptic mechanisms. J Neurophysiol, Vol. 68, No. 6, pp. 2016-2025, ISSN 0022-3077

Snow, R. \& Dudek, F. (1986). Evidence for neuronal interactions by electrical field effects in the CA3 and dentate regions of rat hippocampal slices. Brain Res, Vol. 367, No. 1-2, (March), pp. 292-295, ISSN 0006-8993

Somjen, G.; Aitken, P.; Giacchino, J. \& McNamara, J. (1985). Sustained potential shifts and paroxysmal discharges in hippocampal formation. J Neurophysiol, Vol. 53, No. 4, (April), pp.1079-1097, ISSN 0022-3077

Stringer, J.; Williamson, J. \& Lothman, E. (1989). Induction of paroxysmal discharges in the dentate gyrus: frequency dependence and relationship to afterdischarge production. J Neurophysiol, Vol. 62, No. 1, (July), pp. 126-135, ISSN 0022-3077

Stringer, J. \& Lothman, E. (1991). Cholinergic and adrenergic agents modify the initiation and termination of epileptic discharges in the dentate gyrus. Neuropharmacology Vol. 30, No.1, (January), pp. 59-65, ISSN 0028-3908

Sychrová, H. (2004). Yeast as a model organism to study transport and homeostasis of alkali metal cations. Physiol Res, Vol. 53, No. Suppl 1, pp. S91-S98, ISSN 0862 - 8408

Tas, P.; Massa, P.; Kress, H. \& Koschel, K. (1987). Characterization of an $\mathrm{Na}^{+} / \mathrm{K}^{+} / \mathrm{Cl}^{-}$cotransport in primary cultures of rat astrocytes. Biochim Biophys Acta, Vol. 903, No. 3, (October), pp. 411-416, ISSN 0006-3002

Taylor, C. \& Dudek, F. (1982). Synchonous neural afterdischarges in rat hippocampal slices without active chemical synapses. Science, Vol. 218, No. 4574, (November), pp. 810812, ISSN 0036-8075

Taylor, C. \& Dudek, F. (1984). Synchronization without active chemical synapses during hippocampal afterdischarges. J Neurophysiol, Vol. 52, No. 1, (July), pp. 143-155, ISSN 0022-3077

Xiong, Z. \& Stringer, J. (2000). Sodium Pump Activity, not Glial Spatial Buffering, clears Potassium after Epileptiform Activity Induced in The Dentate Gyrus. J. Neurophysiol, Vol. 83, No. :1443-1451, ISSN 0022-3077 


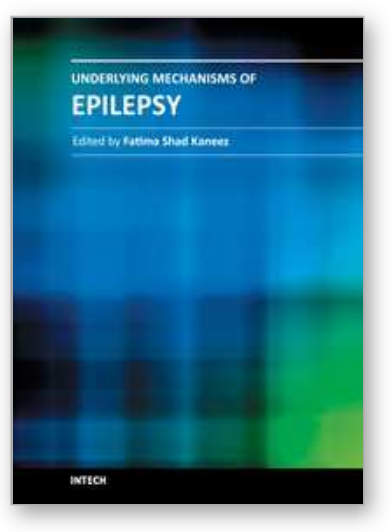

\author{
Underlying Mechanisms of Epilepsy \\ Edited by Prof. Fatima Shad Kaneez
}

ISBN 978-953-307-765-9

Hard cover, 354 pages

Publisher InTech

Published online 26, September, 2011

Published in print edition September, 2011

This book is a very provocative and interesting addition to the literature on Epilepsy. It offers a lot of appealing and stimulating work to offer food of thought to the readers from different disciplines. Around $5 \%$ of the total world population have seizures but only $0.9 \%$ is diagnosed with epilepsy, so it is very important to understand the differences between seizures and epilepsy, and also to identify the factors responsible for its etiology so as to have more effective therapeutic regime. In this book we have twenty chapters ranging from causes and underlying mechanisms to the treatment and side effects of epilepsy. This book contains a variety of chapters which will stimulate the readers to think about the complex interplay of epigenetics and epilepsy.

\title{
How to reference
}

In order to correctly reference this scholarly work, feel free to copy and paste the following:

Antônio-Carlos G. Almeida, Antônio M. Rodrigues, Mário A. Duarte, Gilcélio da Silveira, Fulvio A. Scorza, Ricardo M. Arida, Jaderson C. Costa and Esper A. Cavalheiro (2011). Biophysical Aspects of the Nonsynaptic Epileptiform Activity, Underlying Mechanisms of Epilepsy, Prof. Fatima Shad Kaneez (Ed.), ISBN: 978-953307-765-9, InTech, Available from: http://www.intechopen.com/books/underlying-mechanisms-ofepilepsy/biophysical-aspects-of-the-nonsynaptic-epileptiform-activity

\section{INTECH}

open science | open minds

\section{InTech Europe}

University Campus STeP Ri

Slavka Krautzeka 83/A

51000 Rijeka, Croatia

Phone: +385 (51) 770447

Fax: +385 (51) 686166

www.intechopen.com

\section{InTech China}

Unit 405, Office Block, Hotel Equatorial Shanghai

No.65, Yan An Road (West), Shanghai, 200040, China

中国上海市延安西路65号上海国际贵都大饭店办公楼 405 单元

Phone: +86-21-62489820

Fax: $+86-21-62489821$ 
(C) 2011 The Author(s). Licensee IntechOpen. This chapter is distributed under the terms of the Creative Commons Attribution-NonCommercialShareAlike-3.0 License, which permits use, distribution and reproduction for non-commercial purposes, provided the original is properly cited and derivative works building on this content are distributed under the same license. 